\title{
Incoherent Feed-Forward Regulatory Loops Control Segregation of C-Mechanoreceptors, Nociceptors, and Pruriceptors
}

\author{
(DShan Lou, ${ }^{1,2}$ Xiaoxin Pan, ${ }^{3}$ Tianwen Huang, ${ }^{1,2}$ Bo Duan, ${ }^{1,2}$ Fu-Chia Yang, ${ }^{1,2}$ Juan Yang, ${ }^{3}$ Mulin Xiong, ${ }^{1}$ Yang Liu, ${ }^{3}$ \\ and Qiufu $\mathrm{Ma}^{1,2}$ \\ ${ }^{1}$ Dana-Farber Cancer Institute and ${ }^{2}$ Department of Neurobiology, Harvard Medical School, Boston, Massachusetts 02115, and ${ }^{3}$ Zhejiang Key Laboratory of \\ Organ Development and Regeneration, Institute of Developmental and Regenerative Biology, College of Life Sciences, Hangzhou Normal University, \\ Hangzhou 310029, People's Republic of China
}

\begin{abstract}
Mammalian skin is innervated by diverse, unmyelinated C fibers that are associated with senses of pain, itch, temperature, or touch. A key developmental question is how this neuronal cell diversity is generated during development. We reported previously that the runt domain transcription factor Runx1 is required to coordinate the development of these unmyelinated cutaneous sensory neurons, includ-

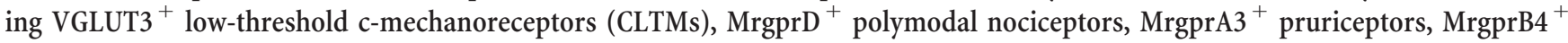
c-mechanoreceptors, and others. However, how these Runx1-dependent cutaneous sensory neurons are further segregated is poorly illustrated. Here, we find that the Runx1-dependent transcription factor gene $Z f p 521$ is expressed in, and required for establishing molecular features that define, VGLUT3 ${ }^{+}$CLTMs. Furthermore, Runx1 and Zfp521 form a classic incoherent feedforward loop (I-FFL) in controlling molecular identities that normally belong to $\mathrm{MrgprD}^{+}$neurons, with Runx1 and Zfp51 playing activator and repressor roles, respectively (in genetic terms). A knock-out of $Z f p 521$ allows prospective VGLUT3 lineage neurons to acquire MrgprD ${ }^{+}$neuron identities. Furthermore, Runx1 might form other I-FFLs to regulate the expression of MrgprA3 and MrgprB4, a mechanism preventing these genes from being expressed in Runx1-persistent VGLUT3 ${ }^{+}$and $\mathrm{MrgprD}^{+}$neurons. The evolvement of these I-FFLs provides an explanation for how modality-selective sensory subtypes are formed during development and may also have intriguing implications for sensory neuron evolution and sensory coding.
\end{abstract}

Key words: low-threshold c-mechanoreceptors; nociceptors; pruriceptors; Runx1; sensory subtype specification; Zfp521

\section{Introduction}

The dorsal root ganglia (DRGs) contain neurons transmitting sensory information related to pain, itch, temperature, and touch and their individual subtypes can be distinguished by differential expression of molecular markers. Expression of MrgprD, a

Received Jan. 11, 2015; revised Feb. 23, 2015; accepted Feb. 27, 2015.

Author contributions:S.L., T.H., B.D., Y.L., and Q.M. designed research;S.L., X.P., T.H., B.D., F.-C.Y., J.Y., M.X., and Y.L. performed research; S.L., X.P., T.H., B.D., F.-C.Y., J.Y., M.X., Y.L., and Q.M. analyzed data; S.L., B.D., F.-C.Y., Y.L., and Q.M. wrote the paper.

Work done in the laboratory of Y.L. was supported by National Natural Science Foundation of China (Grant 31171071). Work done in the laboratory of Q.M. was supported by the National Institutes of Health (National Institute of Dental and Craniofacial Research Grant R01 DE018025 and National Institute of Neurological Disorders and Stroke Grant P01 NS047572). We thank Nancy Speck and Gary Gilliland for the floxed Runx 1 mice, MarkZylka and the Mutant Mouse Regional Resource Centers for the MrgprD-GFP and MrgprD-Cre mice, Xinzhong Dong for the MrgprA3-Cre mice, Susan Dymecki for the ROSA26-Flpe deletor mice, the Allen Brain Institute and the Jackson Laboratory for the Rosa26 $6^{\text {LSL - tdTomato }}$ mice, and the Intellectual and Developmental Disabilities Research Center Mouse Gene Manipulation Core at Boston Children's Hospital for the generation of Zfp521 floxed mice.

The authors declare no competing financial interests.

Correspondence should be addressed to either of the following: Yang Liu, Zhejiang Key Laboratory of Organ Development and Regeneration, Institute of Developmental and Regenerative Biology, College of Life Sciences, Hangzhou Normal University, Hangzhou 310029, People's Republic of China, E-mail: Yang_Liu@idrbio.org; or Qiufu Ma, Dana-Farber Cancer Institute, Harvard Medical School, 450 Brookline Avenue, Boston, Massachusetts 02115. E-mail: Qiufu_Ma@dfci.harvard.edu.

DOI:10.1523/JNEUROSCI.0122-15.2015

Copyright $\odot 2015$ the authors $\quad 0270-6474 / 15 / 355317-13 \$ 15.00 / 0$
G-protein-coupled receptor, marks neurons required to sense light punctate mechanical pain and chemical itch evoked by $\beta$-alanine (Zylka et al., 2005; Cavanaugh et al., 2009; Rau et al., 2009; Liu et al., 2012). MrgprB4 ${ }^{+}$c-mechanoreceptors detect massage-like stroking (Vrontou et al., 2013). MrgprA3 ${ }^{+}$nociceptors are dedicated to itch (Liu et al., 2009; Han et al., 2013). The fourth group is the low-threshold c-mechanoreceptors (CLTMs) that are marked by the coexpression of vesicular glutamate transporter 3 (VGLUT3), tyrosine hydroxylase (TH), and the cytokine TAFA4 (Seal et al., 2009; Li et al., 2011; Delfini et al., 2013; Lou et al., 2013). Finally, neurons expressing the transient receptor potential channels, such as TRPM8 and TRPV1, respond to cold and heat stimuli, respectively (Julius, 2013). A challenge in developmental biology is understanding how such cell diversity is generated during development.

The past decades have seen progress in characterizing genetic programs controlling sensory neuron development. C-fiber neurons associated with pain, itch, and thermal sensations are formed during a late wave of neurogenesis (Ma et al., 1999; Bachy et al., 2011; Liu and Ma, 2011; Lallemend and Ernfors, 2012). These neurons are initially marked by the expression of the nerve growth factor receptor TrkA and the runt domain transcription factor Runx1 (Liu and Ma, 2011; Lallemend and Ernfors, 2012). 
During perinatal and postnatal development, Runx1 expression is switched off in $\sim 50 \%$ of these neurons. Functionally, Runx1 is required for the development of a cohort of sensory neurons that preferentially innervate the skin epidermis and hair follicles (Chen et al., 2006; Yoshikawa et al., 2007; Yang et al., 2013; Moqrich, 2014), as summarized in Figure $1 A$.

However, it remains poorly understood how distinct Runx1dependent cutaneous sensory neuron subtypes are segregated. Several transcription factors, including Brn3a, Islet1, Tlx3, and ZBTB20, also play a role in controlling sensory channels and receptors (Sun et al., 2008; Dykes et al., 2010; Lopes et al., 2012; Zou et al., 2012; Ren et al., 2014); however, all of them are expressed in most, if not all, DRG neurons, so this does not explain how modality-selective sensory subtypes develop.

Here, we report our findings that a Runx1-dependent transcription factor, Zfp521, is expressed in one type of Runx1dependent neurons: VGLUT3 ${ }^{+}$CLTMs. The Zfp521 gene encodes a protein composed of 1311 amino acids and 30 Kruppel-like zinc fingers, which has been implicated in controlling bone, adipocyte, and neural development (Hesse et al., 2010; Kamiya et al., 2011; Kang et al., 2012). We demonstrate that Runx1 and Zfp521 form incoherent feedforward loops (I-FFLs) to control the segregation of CLTMs versus $\mathrm{MrgprD}^{+}$nociceptors. In addition, Runx1 might form other I-FFLs to control the segregation of CLTMs from MrgprA3 ${ }^{+}$pruriceptors. Our studies therefore provide insight into the mechanisms that govern the emergence of sensory neurons processing distinct modalities.

\section{Materials and Methods}

Animals. The generation of Runx1 floxed mice (Growney et al., 2005), ROSA26-CAG-LSTOPL-tdTomato reporter mice (Madisen et al., 2010), MrgprD-GFP mice (Zylka et al., 2005), MrgprD-Cre mice (Rau et al., 2009), and MrgprA3-Cre mice (Han et al., 2013) has been described previously. The generation of Vglut3-Cre mice was described previously by the Bradford B. Lowell group. The generation of $Z f p 521$ floxed mice will be described in the next section. Genotyping was done by PCR. The following PCR primers were used for the Runx1 mutant and wild-type allele: 5'-GAG TCC CAG CTG TCA ATT CC- $3^{\prime}$ and 5'-GGT GAT GGT CAG AGT GAA GC-3', with the floxed allele producing a larger size of DNA band; for the Vglut3-Cre allele, 5' -TAT CTC ACG TAC TGA CGG TG- $3^{\prime}$ and $5^{\prime}$-AGA CTA ATC GCC ATC TTC CAG C-3'; for the ROSA26-CAG-LSTOPL-tdTomato allele, 5' -GGC ATT AAA GCA GCG TAT CC-3' and 5'-CTG TTC CTG TAC GGC ATG G-3'. Both females and males were used for the studies and all animal procedures were conducted with protocols approved by the animal care and use committees at Dana-Farber Cancer Institute and Hangzhou Normal University.

Gene targeting in embryonic stem cells and generation of Zfp521 floxed mice. To generate $Z f p 521$ conditional knock-out mice, the $12 \mathrm{~kb}$ genomic DNA fragment containing Zfp521 exon 4 was subcloned from a BAC clone using the recombination system developed by Liu et al. (2003). A Neo cassette flanked with LoxP sites was targeted upstream of exon 4 and subsequent excision of the Neo cassette by Cre-mediated recombination leaves behind a single loxP plus a Pacl restriction enzyme site upstream of exon 4. A new Neo cassette flanked with FRT sites and a downstream LoxP site was then targeted to the region $3^{\prime}$ to the exon 4 . A diphtheria toxin $(D T A)$ cassette located at the $3^{\prime}$ end of the recombination arm was used to drive the expression of the DTA for negative selection. Upon linearization, this targeting vector was electroporated into the J1 embryonic stem (ES) cell line (derived from 129Sv/J mouse strain), with G418 included in the culture medium for positive selection. Long-range PCR amplification was performed to screen for targeted ES clones and the targeted ES cells were injected into the blastocysts derived from C57BL/6J females. Chimeric male mice were mated with C57BL/6J females to generate heterozygous mice carrying the targeted allele. These mice were mated with the Flpe deleter mouse line (Rodríguez et al., 2000) to remove the neo cassette, leading to the creation of the mice carrying the Zfp521 floxed allele, in which the exon 4 is flanked with two Loxp sequences (see Fig. $3 A$ ). The genotyping for the conditional knock-out mice was performed with the following set of primers: for $Z f p 521$ wild-type and floxed allele, 5' ${ }^{\prime}$-AGTGAGCATCGCAGATCTGA- ${ }^{\prime}$ and $5^{\prime}$-TGAGGAAAACC TGGTTGTCT $3^{\prime}$, with the floxed allele showing a larger DNA band after gel electrophoresis.

In situ hybridization and immunohistochemistry. Antisense Zfp521 probe $(1.001 \mathrm{~kb})$, Runx 1 probe $(0.858 \mathrm{~kb})$, VGLUT3 probe $(0.771 \mathrm{~kb})$, TH probe $(0.788 \mathrm{~kb})$, Piezo2 probe $(0.977 \mathrm{~kb})$, MrgprA3 probe $(1.15 \mathrm{~kb})$, MrgprB4 probe $(0.888 \mathrm{~kb})$, MrgprD probe $(1.058 \mathrm{~kb}), \mathrm{P} 2 \mathrm{X} 3$ probe $(1.1$ $\mathrm{kb})$, and TAFA4 probe $(0.75 \mathrm{~kb})$ were amplified from cDNA prepared from adult DRG and labeled with digoxigenin (Roche). The digoxigeninlabeled mGluR5 and SCG10 in situ probes were prepared by in vitro transcription using plasmid DNAs as the templates. For double-color in situ hybridization (ISH), two antisense probes were labeled with digoxigenin and with fluorescein (Roche), respectively. After hybridization, the sections were incubated with peroxidase-conjugated anti-fluorescein antibody (Roche), followed by biotin tyramide (PerkinElmer) treatment and incubation with rhodamine red-conjugated strepavidin (Life Technologies). After taking fluorescent images, alkaline phosphatase (AP)conjugated anti-DIG antibody (Roche) was applied to the sections overnight and in situ signals were developed with AP reaction. After AP development, bright-field images were taken, converted to pseudofluorescence images, and merged with rhodamine red fluorescent images. ISH/immunohistochemistry and ISH/Tomato double staining was performed as described previously (Liu et al., 2008; Liu et al., 2010; Lou et al., 2013). Rabbit anti-Runx1 antibody (1:100; Abcam) was used for Figure 5.

Hairy skin innervation analyses. Back skin $\left(1.5 \times 1.5 \mathrm{~cm}^{2}\right)$ from 3

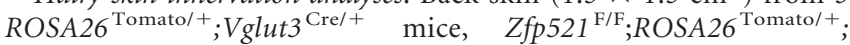
Vglut $3^{\mathrm{Cre} /+}$ mice, $\quad$ Runx $1^{\mathrm{F} / \mathrm{F}} ;$ ROSA $26^{\text {Tomato/+ }} ;$ Vglut $3^{\mathrm{Cre} /+}$ mice, ROSA $26^{\text {Tomato/+ }} ; \mathrm{MrgprA}^{\mathrm{Cre} /+}$ mice, and MrgprD-GFP mice were collected. Back skins were fixed in 4\% PFA, cryoprotected in $20 \%$ sucrose, embedded in OCT, and cut into $30-\mu \mathrm{m}$-thick sections. All sections were counterstained with DAPI (Roche, $1 \mathrm{mg} / \mathrm{ml}$ ) to identify the keratinocyte layers in the epidermis. Tomato ${ }^{+}$nerve fibers were directly visualized under a fluorescent microscope, whereas MrgprD-GFP ${ }^{+} \mathrm{fi}^{-}$ bers were visualized by rabbit anti-GFP immunostaining (1:1000; Invitrogen), as described previously (Yang et al., 2013). To quantify the hair neck region innervation by VGLUT3-Tomato ${ }^{+}$fibers and MrgprA3Tomato $^{+}$fibers, skin sections were first screened under the DAPI channel and only "intact" hairs that started with hair follicle and went all the way through the epidermis were selected for subsequent innervation analyses. We used this unbiased method to collect the images of intact hairs from $>200$ visual fields under a $20 \times$ Zeiss fluorescence microscope. The numbers of intact hairs in the visual field and the numbers of hair neck regions that were innervated by Tomato ${ }^{+}$or $\mathrm{GFP}^{+}$fibers were count. At the same time, free nerve endings in the skin epidermis surrounding these intact hairs and the longitudinal lanceolate endings and circumferential endings wrapped around the hair follicles were examined. The experimenters were blinded to genotype on all of these quantitative analyses.

Cell quantification. Lumbar DRGs (L1-L3) from 2-3 mutant and control mice were dissected bilaterally, fixed, and embedded, and sectioned into sections of $14 \mu \mathrm{m}$ thickness. For each probe, three sets of control and mutant DRG sections were processed for immunostaining or used for ISH with the marker of interest and positive cells with nuclei were counted.

Statistics. Results are expressed as mean \pm SEM. For quantification of histochemistry analysis, data were subjected to the $\chi^{2}$ test. $p<0.05$ was accepted as statistically significant.

\section{Results}

\section{Segregation of Runx1-dependent cutaneous sensory neuron subtypes}

In this study, we studied four subtypes of Runx1-dependent cutaneous sensory neurons: $\mathrm{MrgprD}^{+}$polymodal nociceptors, $\mathrm{MrgprA3}^{+}$pruriceptors, MrgprB4 ${ }^{+}$c-mechanoreceptors, and 
A

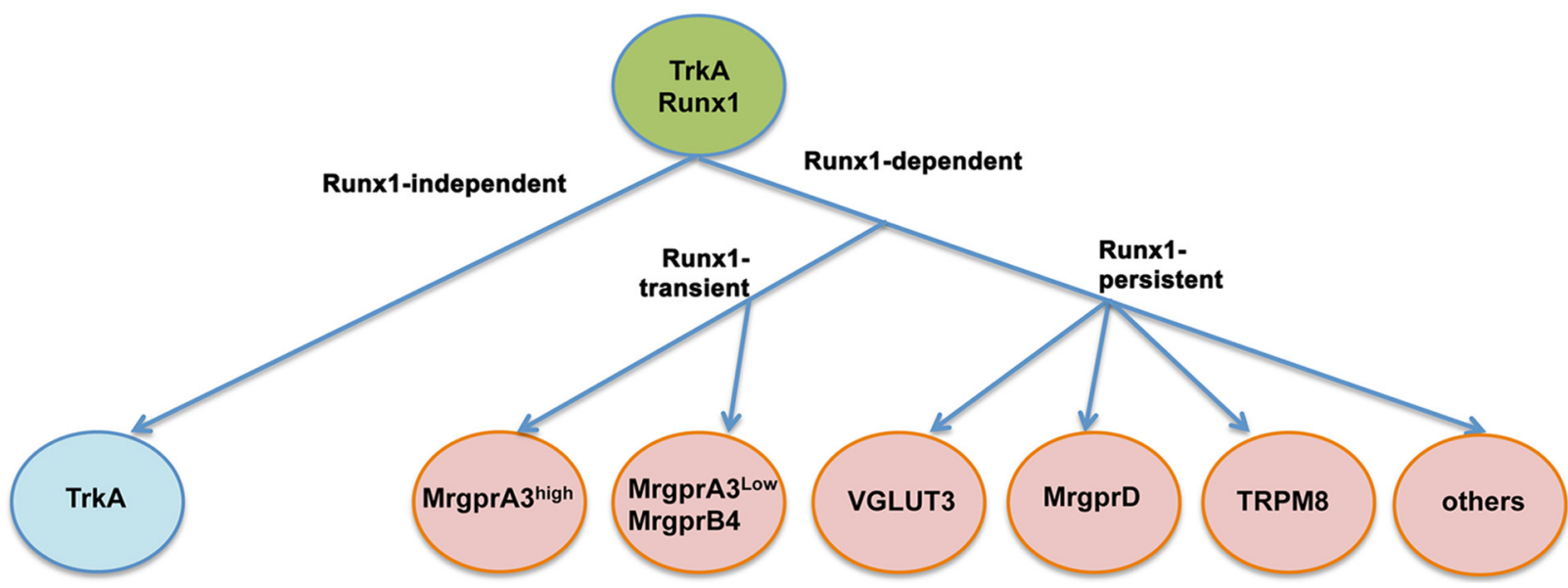

B

B

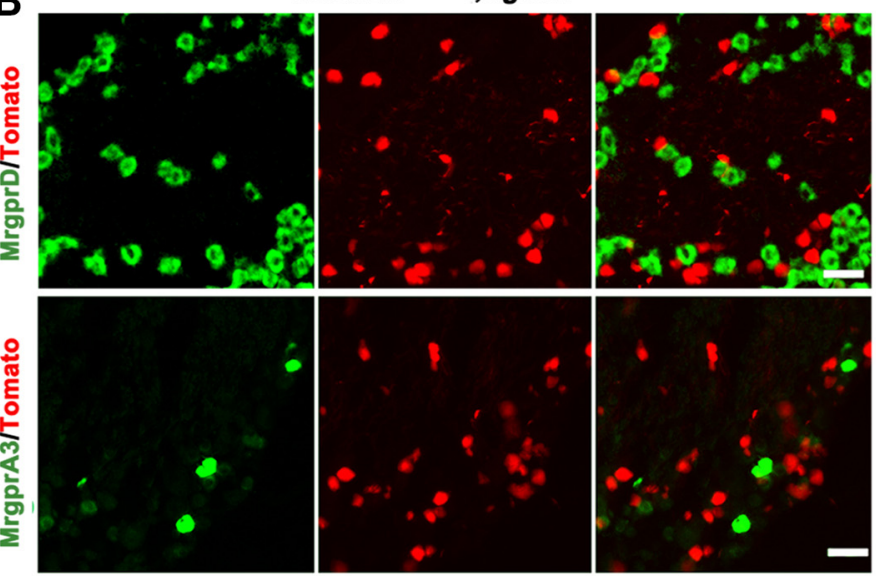

C

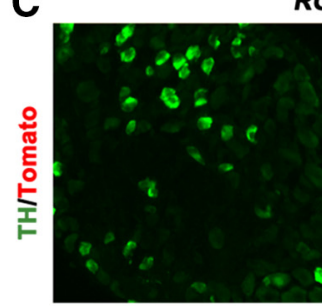

ROSA26 ${ }^{\text {Tomato/+;MrgprA3 }}{ }^{\text {Cre/+ }}$
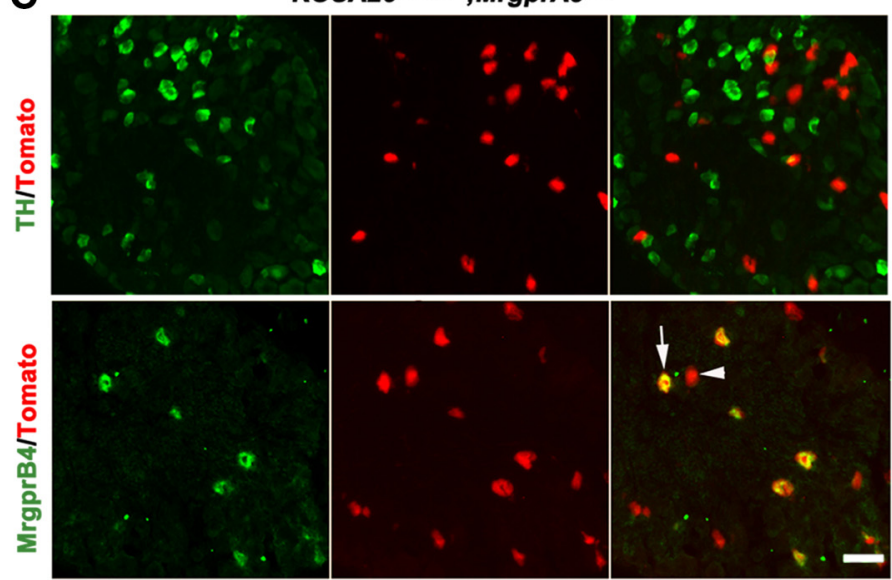

D
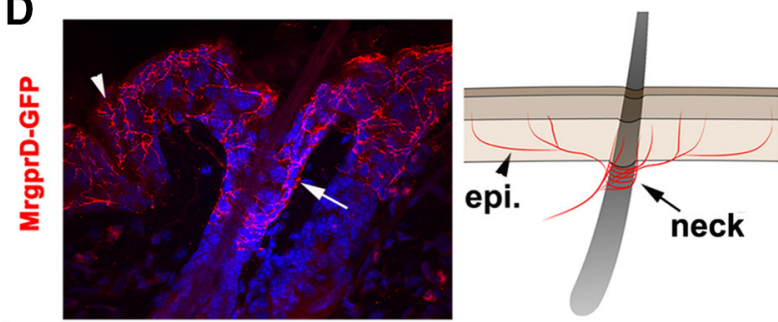

E
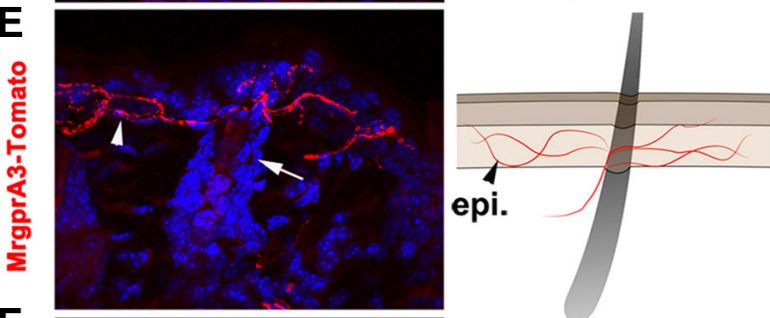

$\mathbf{F}$
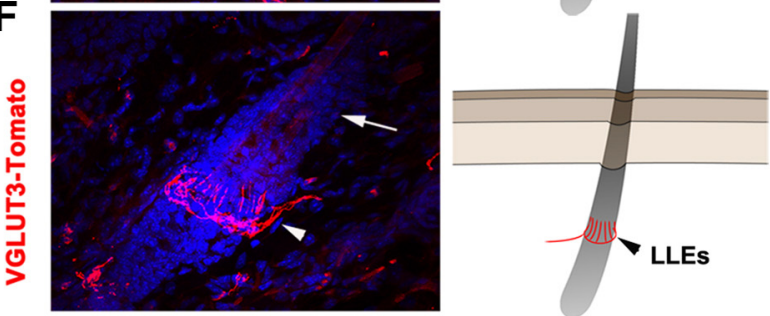

Figure 1. Segregation of Runx1-dependent cutaneous sensory neurons. $A$, Schematics showing the segregation of TrkA lineage neurons. $B$, Transverse sections through P30 lumbar DRG of ROSA26 ${ }^{\text {Tomato } /+} ;$,Vglut $3^{\text {Cre/+ }}$ mice. No MrgprD or MrgprA3 mRNA was detected by ISH in VGLUT3-Tomato ${ }^{+}$neurons. C, Transverse sections through P30 lumbar DRG of ROSA26 ${ }^{\text {Tomato/+ }}$; MrgprA3 $^{\mathrm{Cre} /+}$ mice. Arrow indicates MrgprB4 mRNA detected in a subset of Tomato ${ }^{+}$MrgprA3 lineage neurons. Arrowhead indicates Tomato ${ }^{+}$neurons lacking MrgprB4. D-F, Transverse sections through the hairy skin of P60 MrgprD-GFP mice $(\boldsymbol{D})$, ROSA26 $^{\text {Tomato/+ }} ; \mathrm{MrgprA3}^{\mathrm{Cre} /+}$ mice $(\boldsymbol{E})$, or ROSA26 ${ }^{\text {Tomato/+ }} ; \mathrm{Vglut} 3^{\mathrm{Cre} /+}$ mice $(\boldsymbol{F})$. Arrows indicate the neck region of a hair follicle innervated by MrgprD-GFP ${ }^{+}$fibers $(\boldsymbol{D})$, but not by MrgprA3-Tomato ${ }^{+}$fibers $(\boldsymbol{E})$ or VGLUT3-Tomato ${ }^{+}$fibers $(\boldsymbol{F})$. Arrowheads in $\boldsymbol{D}$ and $\boldsymbol{E}$ indicate epidermal ("epi.") innervations; arrowhead in $\boldsymbol{F}$ indicates LLEs. The schematics in $\boldsymbol{D}-\boldsymbol{F}$ summarize the innervation patterns. Scale bars, $50 \mu \mathrm{m}$.

VGLUT3 $^{+}$CLTMs (Fig. 1A). To assess the lineage relationship among these neurons, we performed fate-mapping experiments. We first crossed VGLUT3-Cre and MrgprA3-Cre mice each with ROSA26-LSL-tdTomato reporter mice (Madisen et al., 2010; Han et al., 2013), with the resulting double heterozygous mice referred to as ${\text { OOSA } 26^{\text {Tomato/+ }} \text {;VGLUT3 }}^{\mathrm{Cre} /+}$ and ROSA $^{\text {Tomato/+ }}$; $M r g p r A 33^{\mathrm{Cre} /+}$, respectively. In these mice, neurons with a developmental history of VGLUT3 or MrgprA3 expression are permanently marked by the expression of the red fluorescent tdTomato protein, so these neurons are referred to as VGLUT3- 
Tomato $^{+}$and MrgprA3-Tomato ${ }^{+}$neurons, respectively. In situ hybridization (ISH) on sections from lumbar DRGs showed that VGLUT3-Tomato $^{+}$neurons virtually do not express MrgprD, MrgprA3, or MrgprB4 (Fig. $1 B$ and data not shown). MrgprA3Tomato $^{+}$neurons do not express MrgprD (data not shown) or TH (Fig. 1C), a marker for VGLUT3 ${ }^{+}$CLTMs (Li et al., 2011; Lou et al., 2013), but some of them do express MrgprB4 (Fig. 1C). The association of MrgprB4 with MrgprA3 lineage neurons is consistent with a previous report showing that MrgprA3 ${ }^{+}$neurons are composed of two subsets distinguished by high or low MrgprA3 expression (MrgprA3 ${ }^{\text {high }}$ or MrgprA3 ${ }^{\text {low }}$ ), with MrgprB4 expression being confined to MrgprA3 ${ }^{\text {low }}$ neurons (Liu et al., 2008). Therefore, the expression of MrgprD, VGLUT3, and MrgprA3 marks three nonoverlapped groups of DRG neurons, with Mrg$\mathrm{prA3}^{+}$neurons being additionally subdivided into MrgprA3 ${ }^{\text {high }}$ neurons that likely represent pruriceptors (Han et al., 2013) and MrgprA3 ${ }^{\text {low }} / \mathrm{MrgprB}^{+}{ }^{+} \mathrm{c}$-mechanoreceptors that are proposed to be associated with pleasant touch evoked by massage-like mechanical stimuli (Vrontou et al., 2013).

$\mathrm{MrgprD}^{+}, \mathrm{MrgprA3}^{+}$, and VGLUT3 ${ }^{+}$neurons all innervate the hairy skin (Zylka et al., 2005; Liu et al., 2007; Li et al., 2011; Han et al., 2013; Lou et al., 2013), but details of their innervation have not yet been fully characterized. To do this, we first examined MrgprD-GFP reporter mice in which $\mathrm{MrgprD}^{+}$neurons are marked by the expression of green fluorescent protein (GFP) (Zylka et al., 2005). Immunofluorescent staining against GFP showed that MrgprD-GFP ${ }^{+}$fibers densely innervate the skin epidermis and wrap around the "neck" of hair follicles (Fig. 1D, arrow). MrgprA3-Tomato ${ }^{+}$neurons from ROSA26 $^{\text {Tomato/+}}$; MrgprA3 ${ }^{\mathrm{Cre} /+}$ mice, the terminals of which can be directly visualized under a fluorescent microscope, also innervate the epidermis throughout the hairy skin, but, unlike MrgprD-GFP ${ }^{+}$ fibers, they rarely innervate the neck of hair follicles (Fig. 1E). VGLUT3-Tomato $^{+}$fibers form longitudinal lanceolate endings (LLEs) around the middle portion of most hair follicles, an area ventral to the neck region (Fig. $1 F$ ). VGLUT3-Tomato ${ }^{+}$fibers also innervate the epidermis, but, unlike the broad distribution of MrgprD-GFP $^{+}$and MrgprA3-Tomato ${ }^{+}$fibers, VGLUT3Tomato $^{+}$epidermal fibers are restricted to the area surrounding a small subset of hairs (see below). In summary, three molecularly distinct Runx1-dependent cutaneous sensory neurons, Mrg$\operatorname{prD}^{+}, \mathrm{MrgprA3}^{+}$, and VGLUT3 ${ }^{+}$, display distinct innervation patterns in the hairy skin (see schematics in Fig. $1 D-F$ ).

\section{Runx1-dependent $Z f p 521$ marks VGLUT3 ${ }^{+}$CLTMs}

To understand how Runx1-dependent sensory subtypes are specified, we screened the Allen Brain Atlas and found that the zinc finger gene $Z f p 521$ is expressed in a subset of DRG neurons, as well as in the CNS, such as the dorsal spinal cord (http://mousespinal.brain-map.org/imageseries/show.html?id = 100012182). In developing DRGs, ISH showed that high-level Zfp521 expression (Zfp521 ${ }^{\text {high }}$ ) was established at embryonic stages between embryonic day 13.5 (E13.5) and E16 (Fig. 2A). In postnatal day (P30) DRGs, Zfp521 ${ }^{\text {high }}$ expression is confined in a subset of neurons (Fig. $2 B$ ). We next found that the number of Zfp52 $1^{\text {high }}$ neurons in P30 lumbar DRG was greatly reduced in Runx1 conditional knock-out mice $\left(\right.$ Runx $1^{\mathrm{F} / \mathrm{F}}$;Wnt1 ${ }^{\mathrm{Cre} /+}$; Fig. $2 B)$, in which Runx1 was removed in the neural crest cells, including sensory precursors (Chen et al., 2006). Double-color ISH of Runx1 and Zfp521 showed that virtually all Zfp521 high neurons $(283 / 293=96.6 \%)$ coexpress Runx1 and $1 / 3$ of Runx1expressing neurons coexpress Zfp521 ${ }^{\text {high }}(283 / 821=34.5 \%)$ in P30 L1-L3 DRGs (Fig. 2C, arrows). In contrast, neurons with low levels of Zfp521 expression do not express Runx1 (Fig. 2C, arrowhead) and, consistently, such low-level expression was still detected in $R u n x 1^{\mathrm{F} / \mathrm{F}}$;Wnt1 ${ }^{\mathrm{Cre} /+}$ mice (Fig. 2B, arrowhead). Therefore, Zfp521 high expression marks a subset of Runx1persistent neurons in adult lumbar DRGs.

As described in Figure 1A, Runx1-dependent neurons include a cohort of cutaneous sensory neuron subtypes. To determine which subtypes of sensory neurons express Zfp521, we performed a series of double staining. We first found that Zfp521 is not expressed in classic nonpeptidergic neurons labeled by the isolectin B4 (IB4) or in classic peptidergic neurons marked by expression of the calcitonin gene-related peptide (data not shown). This expression pattern is reminiscent of that of VGLUT3 $^{+}$CLTMs (Seal et al., 2009; Li et al., 2011; Delfini et al., 2013; Lou et al., 2013). To test this directly, we performed Zfp521 ISH on lumbar DRG sections from P30 ROSA26 ${ }^{\text {Tomato/+; }}$ VGLUT3 ${ }^{\mathrm{Cre} /+}$ reporter mice, in which VGLUT3 lineage neurons are marked by Tomato expression. We found that 79.5\% (265/ 333) of Zfp52 $1^{\text {high }}$ neurons are Tomato ${ }^{+}$and $73.0 \%(1105 / 1512)$ of VGLUT3-Tomato ${ }^{+}$neurons express Zfp521 (Fig. 2D, arrows). In thoracic DRGs, Zfp521 $1^{\text {high }}$ was detected in $\sim 61 \%$ of VGLUT3-Tomato $^{+}$neurons (data not shown). Note that those Tomato $^{+}$neurons with the smallest cell diameters either do not express or express low levels of Zfp521 (Fig. 2D, arrowheads). We reported previously that VGLUT3 lineage DRG neurons are heterogeneous, with $85 \%$ and $15 \%$ of them expressing VGLUT3 persistently and transiently, respectively (Lou et al., 2013). The VGLUT3-persistent portion represents CLTMs that express Runx1 persistently, 2/3 of which can be marked by the expression of TH (Lou et al., 2013). We found here that $>80 \%$ (154/192) of Zfp52 $1^{\text {high }}$ neurons coexpress TH (Fig. 2E). It should be noted that there is an early wave of TH expression in embryonic DRG, the expression of which is downregulated during postnatal development (Lagerström et al., 2010). We found that these early $\mathrm{TH}^{+}$ neurons do not express Zfp521 (data not shown). Therefore, Zfp521 high expression selectively marks the $\mathrm{TH}^{+}$subset of $\mathrm{VGLUT3}^{+}$CLTMs that emerge mainly during postnatal development and their lineage relationship with embryonic $\mathrm{TH}^{+}$neurons remains unclear. The association of Zfp521 with VGLUT3 ${ }^{+}$ CLTMs is supported by recent gene expression profiling analyses (Usoskin et al., 2014).

\section{Requirement of $Z f p 521$ for VGLUT3 ${ }^{+}$CLTM development}

To determine the role of $\mathrm{Zfp} 521$ in controlling the specification of these neurons, we generated a mouse line containing a conditional null allele of $Z f p 521$, which is referred to as $Z f p 521^{\mathrm{F} / \mathrm{F}}$ (Fig. $3 A$ ). In this allele, the $3.3 \mathrm{~kb}$ exon 4 is flanked by two loxP sequences and can be removed by Cre-mediated DNA recombination. By crossing Zfp521 ${ }^{\mathrm{F} /+}$ mice with VGLUT3-Cre mice and after further crossing, we created $Z f p 521$ conditional knock-out (CKO) mice in which $Z f p 521$ is selectively removed in VGLUT3 lineage neurons. These CKO mice are referred to as $Z f p 521^{\mathrm{F} / \mathrm{F}}$; Vglut $3^{\mathrm{Cre} /+}$. To label the VGLUT3 lineage neurons with the Tomato reporter, we further generated CKO mice that carry the ROSA26-LSL-tdTomato reporter allele, referred to as $Z f p 521^{\mathrm{F} / \mathrm{F}}$; ROSA $26^{\text {Tomato/+ }} ; \mathrm{Vglut}^{\mathrm{Cre} /+}$ mice. ISH using the deleted exon 4 as the probe revealed a marked loss of $\mathrm{Zfp} 521^{\text {high }}$ neurons (Fig. $3 B$ ). The detection of a few remaining Zfp521 high neurons is consistent with the fact that not all Zfp52 $1^{\text {high }}$ neurons belong to the VGLUT3 lineage.

We next examined how the development of CLTMs was affected in the $Z f p 521$ knock-out. ISH revealed marked decrease of VGLUT3 expression in lumbar DRGs of $Z f p 521^{\mathrm{F} / \mathrm{F}} ;$ Vglut $^{\mathrm{Cre} /+}$ 
A

E13.5

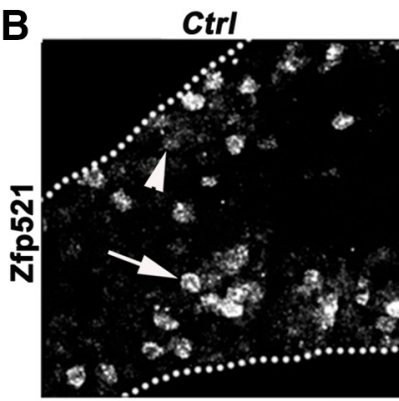

C
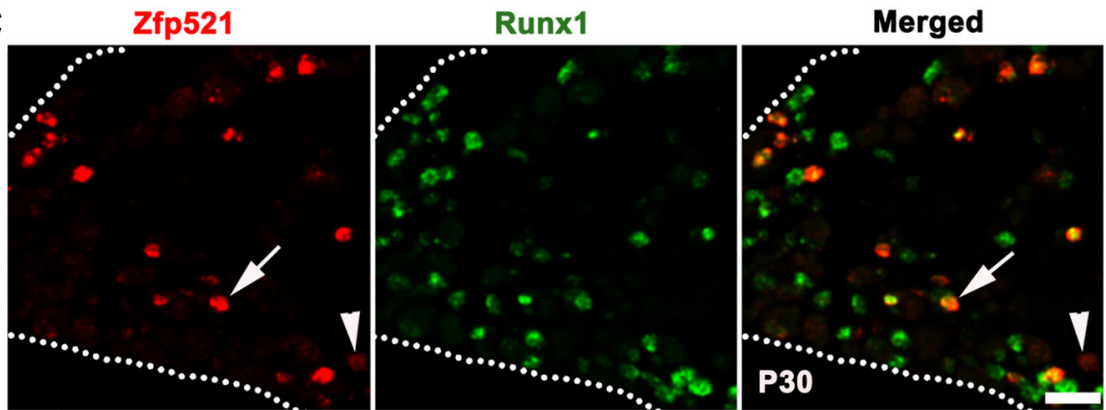

D

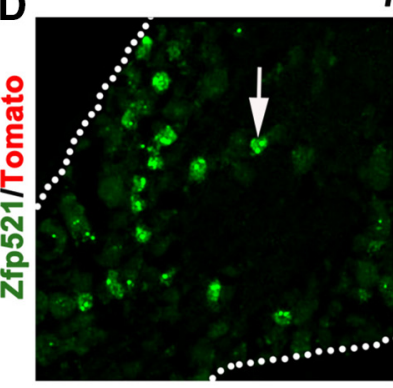

ROSA26 ${ }^{\text {Tomato/+}} ;$ Vglut3 ${ }^{\text {Cre/+ }}$
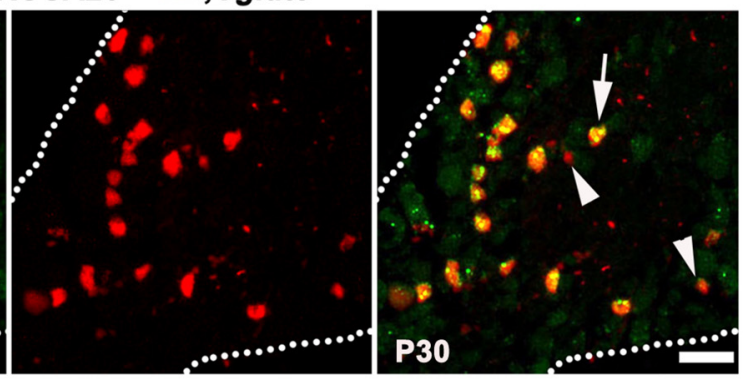

E
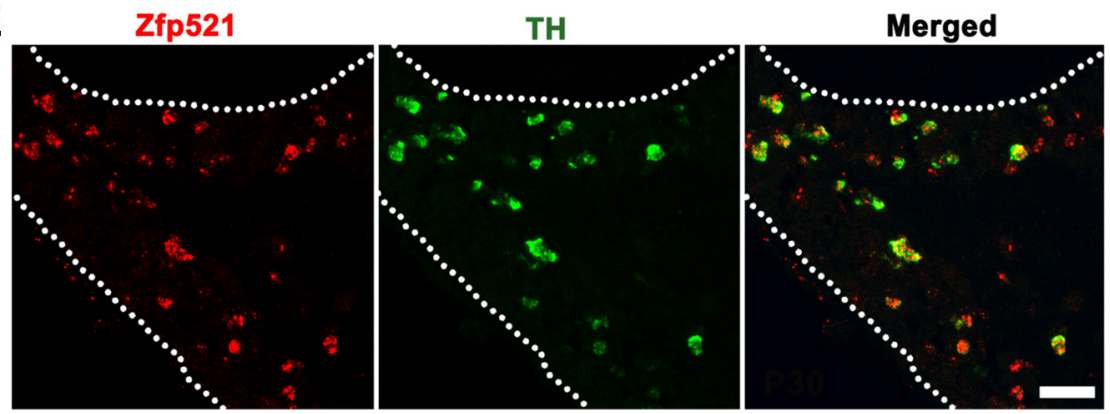

Figure 2. Runx1-dependent Zfp521 marks mainly TH ${ }^{+}$VGLUT3 lineage neurons. $\boldsymbol{A}, \boldsymbol{B}$, Zfp521 mRNA detected by ISH on transverse sections through E13.5 or E16 lumbar DRGs of wild-type embryos $(\boldsymbol{A})$, P30 lumbar DRGs of wild-type control mice ( $\boldsymbol{B}$ "Ctrl"), and Runx $1^{\mathrm{F} / \mathrm{F}} ; \mathrm{Wnt} 1^{\mathrm{Cre} /+}$ CKO mice ( $\boldsymbol{B}$, right). Arrow and arrowheads in $\boldsymbol{B}$ indicate $Z \mathrm{fp} 521^{\text {high }}$ and $\mathrm{Zfp} 521^{\text {low }}$ expression, respectively. C, Double-color ISH on sections through P30 lumbar DRG of wild-type mice. Arrow indicates neurons coexpressing Zfp521 and Runx1. Arrowhead indicates a Zfp521 ${ }^{\text {low }}$ neuron not coexpressing Runx1. D, Zfp521 ISH on a section through P30 lumbar DRG of ROSA26 ${ }^{\text {Tomato/+ }}$;Vglut3 ${ }^{\text {Cre/++}}$ mice. Arrows indicate coexpression of Zfp521 mRNA in VGLUT3-Tomato ${ }^{+}$neurons. Arrowheads indicate Tomato ${ }^{+}$neurons with smallest cell diameters and expressing little or none of Zfp521. E, Double-color ISH on sections through P30 lumbar DRG of wild-type mice indicating coexpression of Zfp521 and TH. Scale bars, $50 \mu \mathrm{m}$.
CKO mice compared with the wild-type control (Fig. 3C). Only few VGLUT3 ${ }^{+}$ neurons remained in the mutant DRGs (Fig. 3C, arrow), consistent with the fact that Zfp521 ${ }^{\text {high }}$ is not expressed in all of VGLUT3 lineage neurons (Fig. 2). The loss of VGLUT3 expression was not due to loss of VGLUT3 lineage cells that were marked by Tomato expression because the percentage of Tomato ${ }^{+}$neurons over the pan-neuronal marker SCG10 (Stein et al., 1988) (detected by ISH) in L1-L3 DRGs was comparable between $Z f p 521^{\mathrm{F} / \mathrm{F}}$; ROSA $26^{\text {Tomato/+ }} ; V_{\text {glut }}{ }^{\mathrm{Cre} /+} \mathrm{CKO}$ mice and ROSA $26^{\text {Tomato/+ }} ;$ Vglut $^{\text {Cre/+ }}$ control mice $(19.6 \pm 1.2 \%$ in control, and $19.1 \pm$ $2.4 \%$ in $\mathrm{CKO}$ mice, $p>0.05)$. In these CKO mice, $Z f p 521$ knock-out occurs after the onset of VGLUT3-Cre expression. The loss of VGLUT3 in Zfp521 $1^{\mathrm{F} / \mathrm{F}}$; Vglut ${ }^{\mathrm{Cre} /+} \mathrm{CKO}$ mice therefore suggests that Zfp521 is required to maintain VGLUT3 expression. Future knock-out of $Z f p 521$ at early embryonic stages is needed to determine whether the initiation of VGLUT3 expression is dependent on Zfp521.

We reported previously that Runx 1 controls other molecular features in VGLUT3 $^{+}$CLTMs in addition to VGLUT3 itself (Lou et al., 2013). We first examined $\mathrm{TH}$ expression and found that the percentage of $\mathrm{TH}^{+}$neurons in VGLUT3-Tomato ${ }^{+}$neurons was significantly reduced in $Z f p 521$ mutant mice (Fig. 3D), from 59.9\% (904/1560) in ROSA $26^{\text {Tomato/+ }} ; V_{\text {glut }}{ }^{\text {Cre/+ }}$ control mice to $32.8 \%(800 / 2437)$ in $Z f p 521^{\mathrm{F} / \mathrm{F}}$; ROSA $26^{\text {Tomato/+ }} ;$ Vglut $3^{\text {Cre/+ }}$ CKO mice, or a $47 \%$ loss of $\mathrm{TH}^{+}$neurons ( $\chi^{2}$ test, $p<0.001)$. TH expression was also reduced by $\sim 38 \%$ in thoracic DRG (data not shown). TAFA4, a cytokine involved with pain modulation, is expressed mainly in $\mathrm{TH}^{+}$CLTMs (Delfini et al., 2013). We found that TAFA4 expression in VGLUT3-Tomato ${ }^{+}$neurons is also reduced in $Z f p 521$ CKO mice (Fig. $3 E$ ), from $55.1 \%(826 / 1499)$ in ROSA26 $6^{\text {Tomato/+ }}$; Vglut $^{\mathrm{Cre} /+}$ control mice to $25.1 \%$ (231/920) in $Z f p 521^{\mathrm{F} / \mathrm{F}} ;$ ROSA $^{\text {Tomato/+ }} ;$ Vglut3 ${ }^{\mathrm{Cre} /+} \mathrm{CKO}$ mice, or a $54.4 \%$ loss ( $\chi^{2}$ test, $\left.p<0.001\right)$. The loss of TH and TAFA4 expression in Zfp521 CKO mice is, however, less than that seen in Runx1 CKO mice $\left(R u n x 1^{\mathrm{F} / \mathrm{F}}\right.$; ROSA ${ }^{\text {Tomato/+ }} ;$ Vglut $\left.^{\mathrm{Cre} /+}\right)$, in which only $15.8 \%(235 / 1484)$ and $8.0 \%(81 /$ 1014) of Tomato ${ }^{+}$neurons retain $\mathrm{TH}$ and TAFA4 expression, respectively (data not shown), compared with the $32.8 \%$ and $25.1 \%$ retained in $Z f p 521 \mathrm{CKO}$ mice, respectively ( $\chi^{2}$ test, $p<0.001$ ). The difference between $Z f p 521$ versus Runx1 CKO 

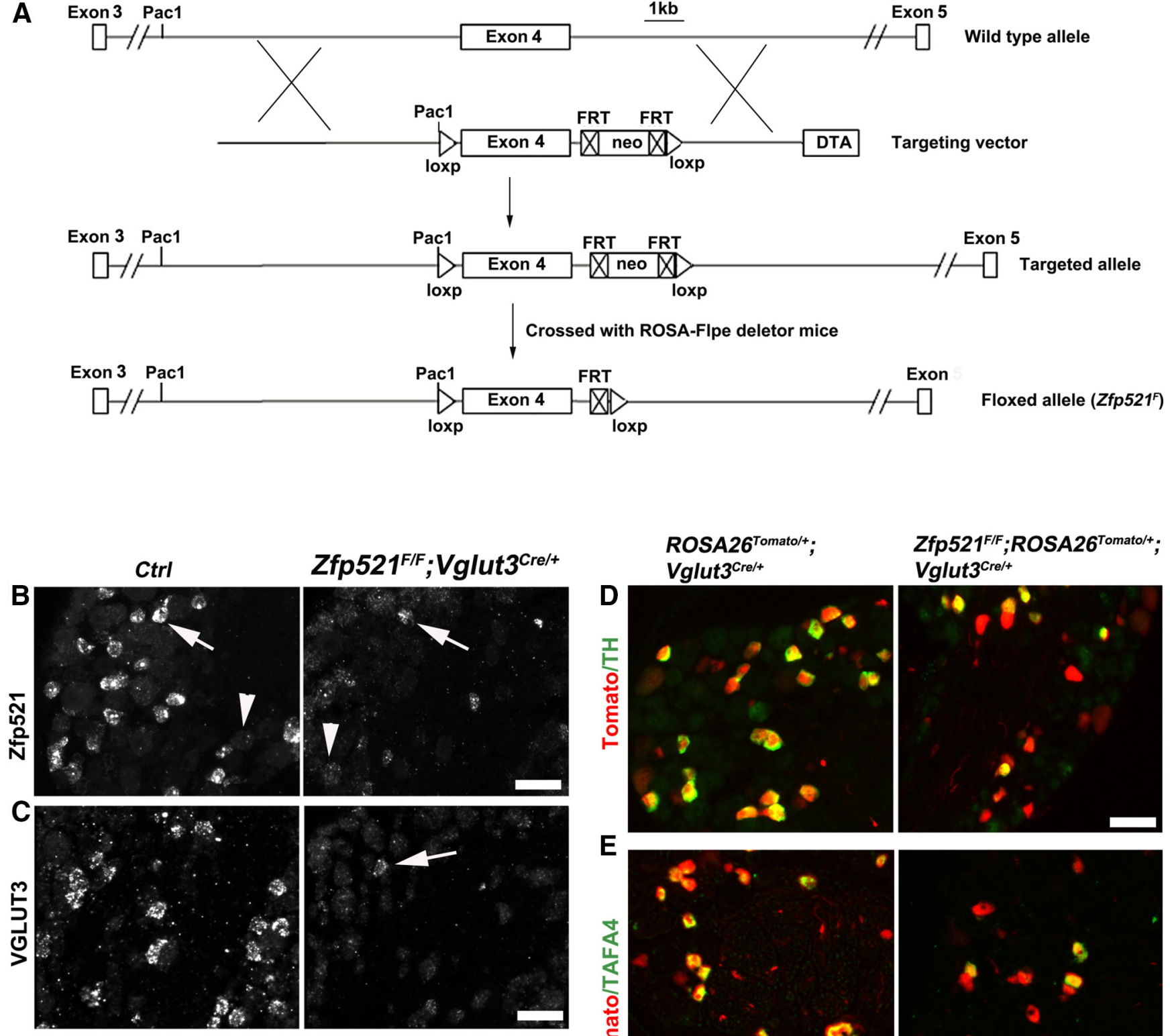

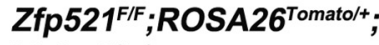

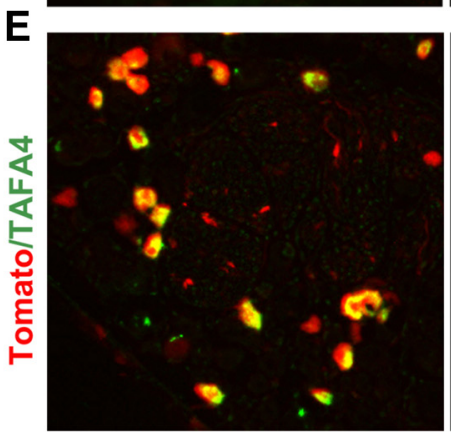

Vglut3 ${ }^{\text {Cre/ }}$

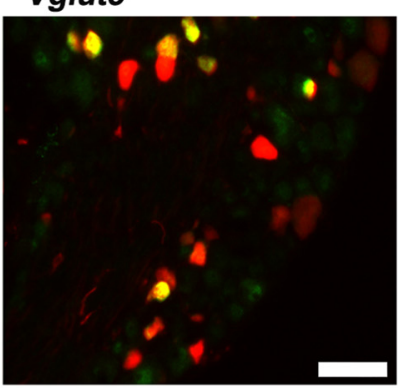

Figure 3. Generation of Zfp521 CKO mice and impaired development of VGLUT3 ${ }^{+}$CLTMs. A, Schematics showing the creation of mice carrying the Zfp521 conditional null allele ("floxed allele" or Zfp52 $27^{\mathrm{F}}$ ). The "DTA" negative selection cassette drives the expression of the diphtheria toxin gene. The "neo" positive selection cassette was flanked with FRT sites and was removed by crossing with ROSA26-Flpe mice. Exon 4 was flanked with two Loxp sites for conditional knockout after crossing with Cre mouse lines. B, C, ISH with indicated probes on sections through P30 lumbar DRG of

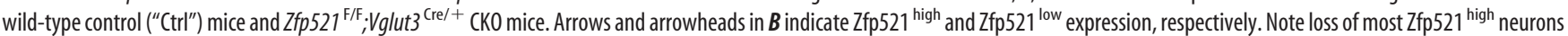
in CKO mice. D, E, Double detection of Tomato plus TH or TAFA4 mRNA on sections through P30 lumbar DRG of control littermate mice (ROSA26 ${ }^{\text {Tomato/+ }}$; Vglut ${ }^{\text {Cre/+ }}$ ) and Zfp521 CKO mice

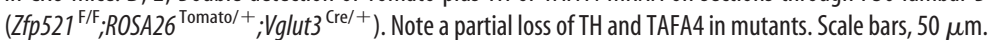

mice is also indicated by the observation that expression of Piezo2 in VGLUT3-Tomato ${ }^{+}$neurons, which is dependent on Runx1 (Lou et al., 2013), is largely unaffected in $Z f p 521^{\mathrm{F} / \mathrm{F}}$; ROSA $26^{\text {Tomato/+ }} ;$ Vglut $3^{\text {Cre/+ }}$ CKO mice (data not shown). Furthermore, skin innervation by VGLUT3 lineage neurons, which is impaired in Runxl CKO mice (see below), is largely unchanged in Zfp521 CKO mice (see Fig. 6C). Therefore, Zfp521 plays an essential role in establishing a portion of Runx1-dependent molecular features in VGLUT3 ${ }^{+}$CLTMs, including the expression of VGLUT3 and a portion of TH and TAFA4, but Runx1 uses Zfp521-independent pathways to control Piezo2, a separate portion of TH and TAFA4, and skin innervations.
CLTMs acquired molecular identities of $\mathrm{MrgprD}^{+}$neurons in Zfp521 CKO mice

Because Zfp521 is a downstream target of Runx1, it is not surprising that Runx1 expression itself is unaffected in $Z f p 521$ CKO mice (Fig. 4A). As illustrated in Figure 1A, Runx1 is required for the development of a large cohort of cutaneous sensory neurons. We next investigated whether, in the absence of Zfp521, Runx1 could drive prospective CLTMs to differentiate into other types of Runx1-dependent neurons. To test this, we looked at the expression of markers of other cutaneous sensory neuron subtypes in VGLUT3-Tomato ${ }^{+}$neurons in control and Zfp521 CKO mice. 


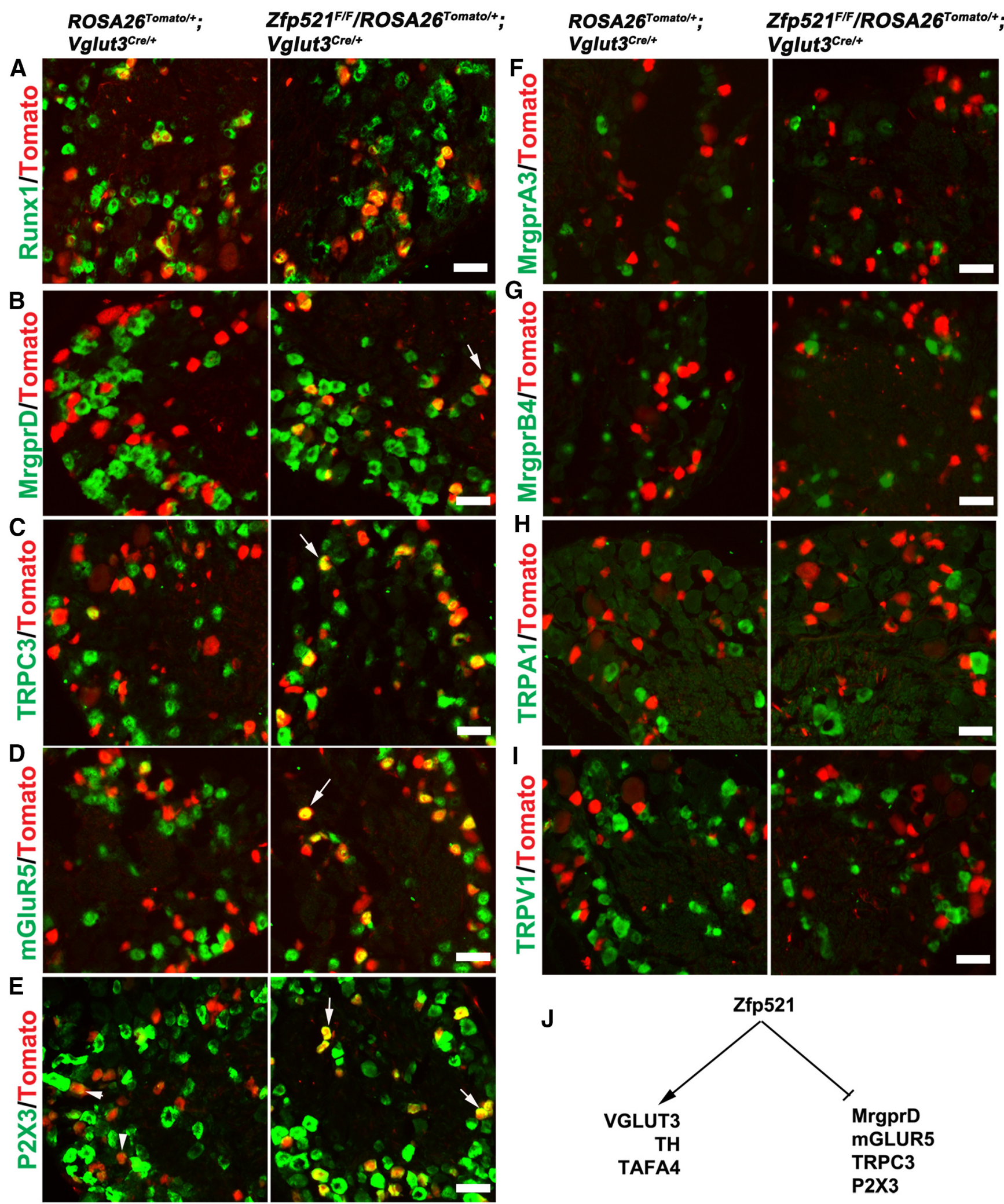

Figure 4. Prospective VGLUT3 lineage neurons acquire molecular features of MrgprD ${ }^{+}$nociceptors in Zfp521 CKO mice. A-I, Double staining of Tomato with indicated mRNAs detected by ISH on sections

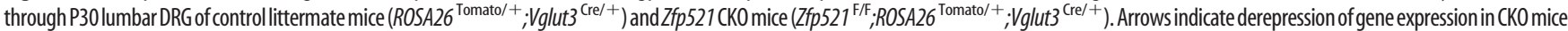
$(\boldsymbol{B}-\boldsymbol{E})$. Arrowheads in $\boldsymbol{E}$ indicate low P2X3 expression in VGLUT3-Tomato ${ }^{+}$neurons in control mice. $\boldsymbol{F}$-lindicate no derepression of these markers.J, Summany of dual functions of Zfp521. Scale bars, $50 \mu \mathrm{m}$.

Like VGLUT3 ${ }^{+}$CLTMs, a majority of $\mathrm{MrgprD}^{+}$nociceptors express Runx1 persistently (Liu et al., 2008). These neurons are marked by the expression of a series of channels and receptors, including MrgprD itself, the ATP-gated ion channel P2X3, the glutamate receptor mGluR5, and the transient receptor potential channel TRPC3, with the expression of all of these genes being dependent on Runx1 (Dong et al., 2001; Chen et al., 2006; Abdel Samad et al., 2010). In Rosa $26^{\text {Tomato/+ }} ;$ Vglut $3^{\text {Cre/+ }}$ control mice, 


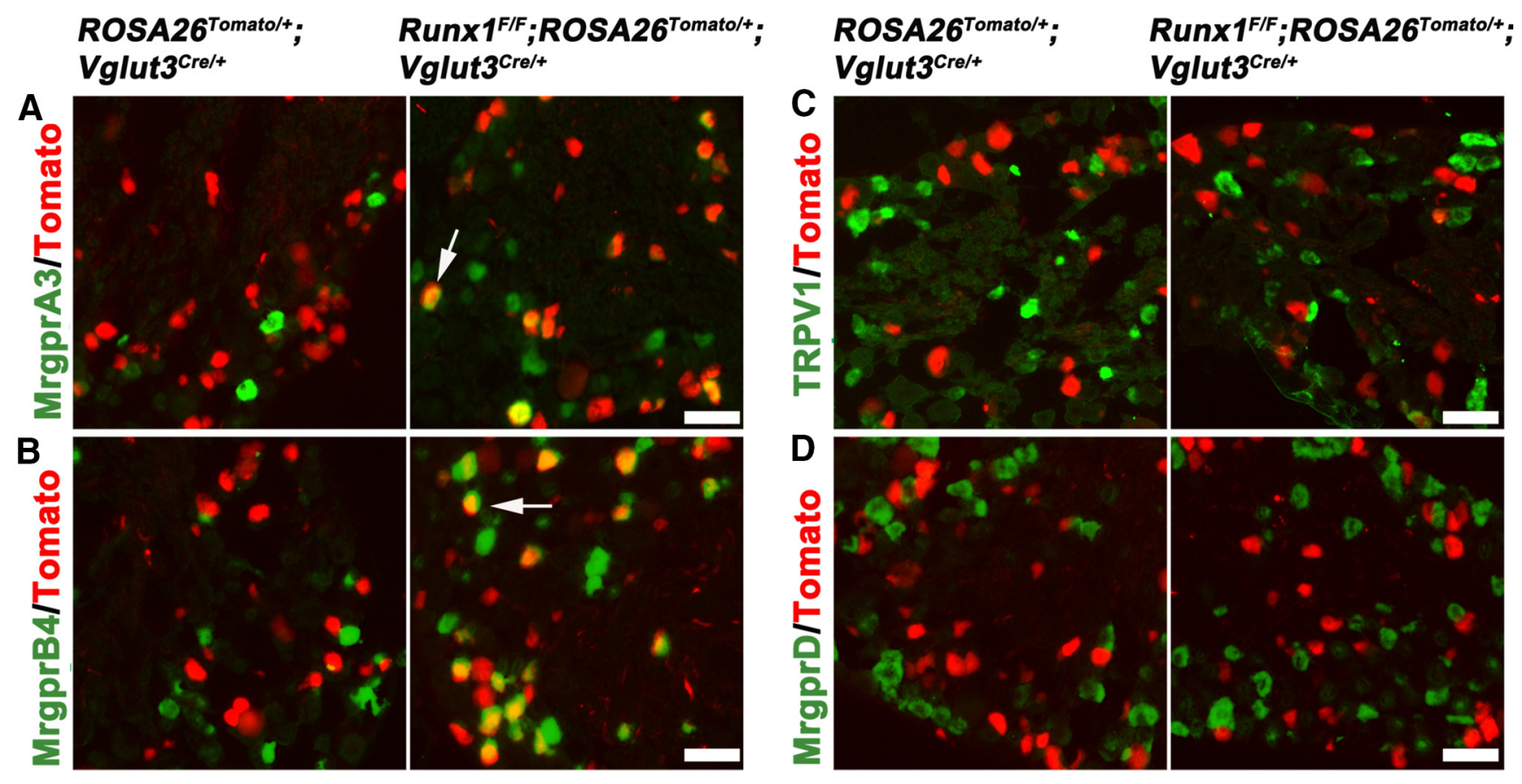

Figure 5. Prospective VGLUT3 lineage neurons acquire identities of MrgrpA3/B4 ${ }^{+}$neurons in Runx 1 late CKO mice. $\boldsymbol{A}-\boldsymbol{D}$, Double staining of Tomato with indicated mRNAs (detected by ISH) on

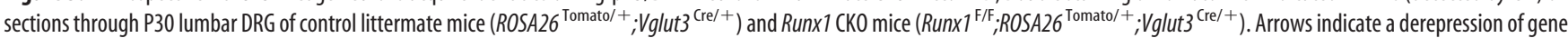
expression in CKO mice $(\boldsymbol{A}, \boldsymbol{B})$. $C$ and $\boldsymbol{D}$ indicate no derepression of these two markers. Scale bars, $50 \mu \mathrm{m}$.

expression of these four genes in VGLUT3-Tomato ${ }^{+}$neurons (Fig. 4B-E, left) is either not detectable, such as MrgprD (Fig. 4B), or is detected at low levels, such as $\mathrm{P} 2 \mathrm{X} 3$ (Fig. 4E, arrowheads; in comparison with surrounding neurons with high-level P2X3 expression). In $Z f p 521^{\mathrm{F} / \mathrm{F}} ;$ Rosa $26^{\text {Tomato/+ }} ;$ Vglut $3^{\mathrm{Cre} /+}$ CKO mice, the expression of MrgprD, TRPC3, and mGLUR5 is expanded into, and the P2X3 expression levels are elevated in, a portion of Tomato $^{+}$neurons (Fig. 4B-E, right). Quantitative analyses showed that MrgprD mRNA was detected in $<2 \%(25 / 1370)$ of VGLUT3-Tomato $^{+}$in control mice, but the percentage was increased to $34.8 \%(493 / 1418)$ in $Z f p 521$ CKO mice ( $\chi^{2}$ test, $p<$ 0.001 ). A similar expansion of MrgprD expression was observed in thoracic DRG (data not shown). Notably, no expansion was observed for those sensory channels and receptors that mark other types of Runx1-dependent neurons listed in Figure $1 A$, such as MrgprA3, MrgprB4, TRPA1, and TRPV1 (Fig. 4F-I). For example, in $Z f p 52^{\mathrm{F} / \mathrm{F}} ;$ Rosa $26^{\text {Tomato/+ }} ;$ Vglut $3^{\mathrm{Cre} /+}$ mice, only $0.9 \%(8 / 877)$ of Tomato ${ }^{+}$neurons expressed MrgprA3, comparable to the $2.0 \%(22 / 1087)$ observed in Rosa26 $6^{\text {Tomato/+ }}$; Vglut $3^{\mathrm{Cre} /+}$ control mice ( $\chi^{2}$ test, $p>0.05$ ). It should be noted that, whereas deep RNA sequencing was able to reveal TRPA1 expression in the $\mathrm{TH}^{+}$subset of VGLUT3 ${ }^{+}$CLTMs (Usoskin et al., 2014), this expression does not reach levels detectable by our in situ hybridization in either wild-type or CKO mice (Fig. 4H). It should also be pointed out that TRPM8 is expressed in the small-

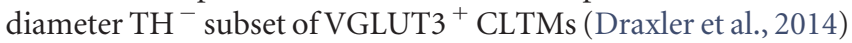
and no obvious loss or expansion of TRPM8 expression was observed in $Z f p 52^{\mathrm{F} / \mathrm{F}}$;Rosa $26^{\text {Tomato/+}} ;$ Vglut $3^{\mathrm{Cre} /+}$ mice compared with control littermates (data not shown), consistent with the enrichment of $\mathrm{Zfp} 521^{\text {high }}$ in $\mathrm{TH}^{+}$CLTMs.

Zfp521, therefore, has dual functions (Fig. $4 J$ ). First, it is required to establish and/or maintain features that are uniquely associated with VGLUT3 ${ }^{+}$CLTMs, such as the full expression of VGLUT3, TH, and TAFA4. Second, it acts as a genetic repressor of Runx1 that prevents VGLUT3 ${ }^{+}$CLTMs from acquiring mo- lecular identities that normally belong to a different type of Runxl-dependent neurons: MrgprD $^{+}$polymodal nociceptors. As shown in Figure $7 A$ and explained in the Discussion (see below), the dual roles of Runx1 in both activating and repressing (through Zfp521) MrgprD indicate that Runx1 and Zfp521 form a classic incoherent feedforward loop (Alon, 2007) to control the segregation of VGLUT3 ${ }^{+}$CLTMs that express Zfp521 versus MrgprD $^{+}$nociceptors that lack Zfp521.

\section{CLTMs acquired identities of MrgprA3 ${ }^{+}$and/or MrgprB4 ${ }^{+}$} neurons in Runx1 late CKO mice

Runx1-dependent cutaneous sensory neurons can be divided into Runx1-persistent and Runx1-transient subpopulations (Fig. 1A). Runx1-persistent neurons include VGLUT3 ${ }^{+}$CLTMs, $\mathrm{MrgprD}^{+}$nociceptors, and others; Runx1-transient neurons include $\mathrm{MrgprA3}^{+}$pruriceptors and $\mathrm{MrgprB}^{+}{ }^{+}$c-mechanoreceptors. The above studies show that, upon the conditional knock-out of Zfp521 by crossing with VGLUT3-Cre mice, in which Cre expression in CLTMs is established at neonatal stages (Lou et al., 2013), prospective VGLUT3 ${ }^{+}$CLTMs are competent to acquire molecular features of $\mathrm{MrgprD}^{+}$neurons. We next investigated whether, upon the neonatal loss of the more upstream transcription factor Runx1 in Runx $1^{\mathrm{F} / \mathrm{F}} ;$ ROSA26 ${ }^{\text {Tomato/+ }}$; Vglut ${ }^{\mathrm{Cre} /+}$ CKO mice, which led to a loss of Zfp521 expression as well (data not shown), prospective VGLUT3 ${ }^{+}$CLTMs are competent to adopt a cell fate that normally undergoes transient Runx1 expression, such as MrgprA3 ${ }^{+}$and/or MrgprB4 ${ }^{+}$neurons. To test this, we performed ISH to analyze MrgprA3 and MrgprB4 expression in the lumbar DRG of Runx1 ${ }^{\mathrm{F} / \mathrm{F}}$; ROSA $26^{\text {Tomato/+ }} ;$ Vglut $^{\text {Cre/+ }}$ mice versus ROSA26 ${ }^{\text {Tomato/+ }}$; Vglut $3^{\mathrm{Cre} /+}$ control mice. We found that the percentage of Tomato $^{+}$neurons expressing MrgprA3 increased from virtually none in ROSA26 ${ }^{\text {Tomato/+ }}$; Vglut $3^{\text {Cre/+ }}$ control mice $(8 / 877=$ $0.9 \%)$ to $34.1 \%(767 / 2249)$ in $R u n \times 1^{\mathrm{F} / \mathrm{F}} ;$ ROSA26 $^{\text {Tomato/+}}$; Vglut $3^{\mathrm{Cre} /+}$ mice $\left(\chi^{2}\right.$ test, $p<0.001$; Fig. $\left.5 A\right)$. Tomato ${ }^{+}$neurons 
expressing MrgprB4 also dramatically increased, from nearly none $(1 / 1523=0.1 \%)$ in control mice to $51.3 \%(835 / 1627)$ in CKO mice ( $\chi^{2}$ test, $p<0.001$; Fig. $5 B$ ). In contrast, expression of other Runx1-dependent genes enriched in Runx1-persistent neurons, such as TRPV1 (Fig. 5C), MrgprD (Fig. 5D), and TRPM8 (data not shown), was not derepressed in Tomato ${ }^{+}$neurons in Runx $1^{\mathrm{F} / \mathrm{F}}$;ROSA ${ }^{\text {Tomato/+ }}$;Vglut $3^{\mathrm{Cre} /+} \mathrm{CKO}$ mice. Therefore, upon the loss of Runxl at perinatal/postnatal stages, a significant proportion of VGLUT3 lineage neurons are competent to acquire molecular identities that normally belong to MrgprA3 ${ }^{+}$or MrgprB4 ${ }^{+}$neurons.

We next investigated whether the changes that we observed in the molecular phenotype of VGLUT3 lineage neurons in our conditional knock-out lines are reflected in the patterns of skin innervation and terminal morphologies. There are three types of VGLUT3-Tomato $^{+}$fibers in the hairy skin. The first one represents fibers from VGLUT3-transient myelinated mechanoreceptors that form the Merkel-cell neurite complexes. As reported previously, this type of innervation is unaffected in $R u n \times 1^{\mathrm{F} / \mathrm{F}}$; ROSA $26^{\text {Tomato/+ }} ;$ Vglut $3^{\mathrm{Cre} /+}$ CKO mice (Lou et al., 2013). The second type forms free nerve endings in the epidermis surrounding 17\% (64/361) of hairs (often in clusters) (Fig. 6A, left). Little innervation was detected in the epidermis surrounding the remaining majority of hairs in control mice (Fig. $6 \mathrm{~A}$, right, small arrowhead). Note that, within the innervated hair clusters, VGLUT3-Tomato $^{+}$fibers also innervated the neck region of the hair follicle (Fig. 6A, left, arrow), as Mrgprd-GFP ${ }^{+}$fibers do (Fig. 1). In Runx $1^{\mathrm{F} / \mathrm{F}} ;$ ROSA $26^{\text {Tomato/+ }} ;$ Vglut3 $3^{\mathrm{Cre} /+} \mathrm{CKO}$ mice, innervation in the neck region of hair follicles and the epidermis surrounding a small subset of hairs is still observed (Fig. 6B, left), indicating that this type of innervation is independent of Runx1. The third type of VGLUT3-Tomato ${ }^{+}$fibers forms longitudinal lanceolate endings (LLEs) in most hair follicles (Fig. 6A, right,

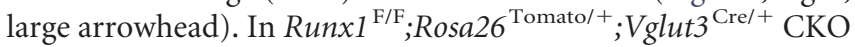
mice, LLEs are lost and became circumferential endings (Fig. $6 B$, right, large arrowhead), as reported previously (Lou et al., 2013). Strikingly, we noticed that Tomato ${ }^{+}$fibers originating from the base of the circumferential endings started to grow superficially (Fig. 6B, right, arrows) and eventually entered the skin epidermis (Fig. $6 B$, right, small arrowhead). As a result, epidermal innervation is now observed throughout the hairy skin. Notably, these fibers do not innervate the hair neck region (Fig. $6 B$, right), a pattern mimicking that of MrgprA3-Tomato ${ }^{+}$fibers described in Figure 1. Therefore both molecularly and anatomically, a portion of VGLUT3 lineage neurons acquire features belonging to MrgprA3 $^{+}$neurons in Runx1 CKO mice. In contrast, no innervation defects were observed upon knock-out of $Z f p 521$ in Zfp521 $1^{\mathrm{F} / \mathrm{F}}$;Rosa $26^{\text {Tomato/+ }}$;Vglut $3^{\mathrm{Cre} /+}$ CKO mice (Fig. 6C), indicating that Zfp521 only controls molecular identities of VGLUT3 $^{+}$CLTMs, but not afferent innervations in the skin.

\section{Discussion}

\section{Zfp521 is necessary for proper development of VGLUT3 ${ }^{+}$ c-mechanoreceptors}

The runt domain transcription factor Runx1 coordinates the development of a large cohort of sensory neurons innervating the skin (Fig. 1A). Our studies support that Runx1 may operate in a cell-context-dependent manner to control the expression of downstream transcription factors that in turn specify sensory neuron subtypes. Specifically, we found that Zfp521, a Runx1dependent transcription factor, is expressed predominantly in the $\mathrm{TH}^{+}$subset of VGLUT3 ${ }^{+}$CLTMs, but not in other Runx1dependent sensory neurons. Zfp521 controls certain Runx1- dependent features in these neurons (Lou et al., 2013), including the expression of VGLUT3 and a portion of TH and TAFA4. However, the expression of the mechanically gated ion channel Piezo2, which is lost in Runxl CKO mice (Lou et al., 2013), is unaffected in Zfp521 CKO mice (data not shown). Furthermore, in Runx1 CKO mice, the lanceolate endings formed by $\mathrm{TH}^{+}$ CLTMs are transformed to become circumferential endings (Lou et al., 2013) and also form free nerve endings that grow into the skin epidermis, a pattern reminiscent of MrgprA3 ${ }^{+}$neurons (Fig. 6). In contrast, such innervation changes do not occur in $Z f p 521$ CKO mice (Fig. 6). Therefore, Runx1 uses both Zfp521dependent and Zfp521-independent pathways to control distinct features of VGLUT3 ${ }^{+}$CLTMs. The loss of molecular identities, without changing skin innervations, also supports distinct genetic programs controlling these developmental processes, as suggested previously (Gorokhova et al., 2014).

\section{I-FFLs control sensory submodality segregation}

I-FFLs are recurring regulatory motifs observed from bacteria to mammals (Alon, 2007). A salient feature of these regulatory loops is that a transcription factor (or a signal) operates through two opposing legs (activation vs repression) in controlling a target gene (Alon, 2007). To our knowledge, our studies reveal for the first time that I-FFLs, in genetic terms, are used to control the segregation of a cohort of mammalian sensory neuron subtypes that innervate distinct parts of the skin, including VGLUT3 ${ }^{+}$ CLTMs, MrgprD ${ }^{+}$polymodal nociceptors, MrgprA3 ${ }^{+}$pruriceptors, and MrgprB4 ${ }^{+}$c-mechanoreceptors (summarized in Fig. 7).

First, Runx1 and Zfp521 form an I-FFL in controlling the molecular identities belonging to $\mathrm{MrgprD}^{+}$polymodal nociceptors. We reported previously that Runxl is required to establish a large molecular program that defines $\mathrm{MrgprD}^{+}$neurons, such as the expression of MrgprD, P2X3, mGLUR5, and TRPC3 (Dong et al., 2001; Chen et al., 2006; Abdel Samad et al., 2010), thereby forming a positive leg for this I-FFL (Fig. 7A). Here, we found that Zfp521, a Runx1-dependent transcription factor, acts as a genetic repressor that prevents Runx1 from activating this molecular program in VGLUT3 ${ }^{+}$CLMRs (Fig. 4), thereby forming an opposing repressor leg for this I-FFL (Fig. $7 A$ ). It should be noted that, temporally, expression of Zfp521 is established at E13.5E16, preceding that of MrgprD, which occurs at E16.5 (Chen et al., 2006; Liu et al., 2008). This precocious onset of the Zfp521mediated repression leg may provide a mechanism that preserves a subset of DRG neurons to develop into prospective VGLUT3 ${ }^{+}$ CLTMs rather than MrgprD ${ }^{+}$neurons. Consistently, MrgrpD lineage neurons, which were marked by crossing MrgprD-Cre mice (Rau et al., 2009) with ROSA26-LSL-tdTomato reporter mice, do not include the $\mathrm{TH}^{+}$subset of VGLUT3 ${ }^{+}$CLTMs (data not shown), indicating no transient MrgprD expression in VGLUT3 $^{+}$CLMRs.

Second, Runxl might form a different I-FFL to control the expression of MrgprA3 and MrgprB4 (Fig. 7B). For this I-FFL, Runx1 itself acts as a genetic repressor but might also form a positive leg by establishing an unknown downstream event "X." The negative leg is clearly indicated by the derepression of MrgprA3/B4 in VGLUT3 ${ }^{+}$CLTMs upon Runx1 knock-out at neonatal stages (Fig. 5). A previous study further showed that Runx1 uses its c-terminal repression domain to suppress MrgprA3/B4 (Liu et al., 2008). The existence of the positive leg and the intermediate $\mathrm{X}$ event is suggested from the following observations. MrgprA3/B4 expression in DRGs is completely lost in Runx $1^{\mathrm{F} / \mathrm{F}}$; Wnt $1^{\mathrm{Cre} /+}$ mice (Chen et al., 2006), in which Runxl is knocked 
A ROSA $^{\text {tdTomato/+; }}$ Vglut3 ${ }^{\text {Cre/+ }}$

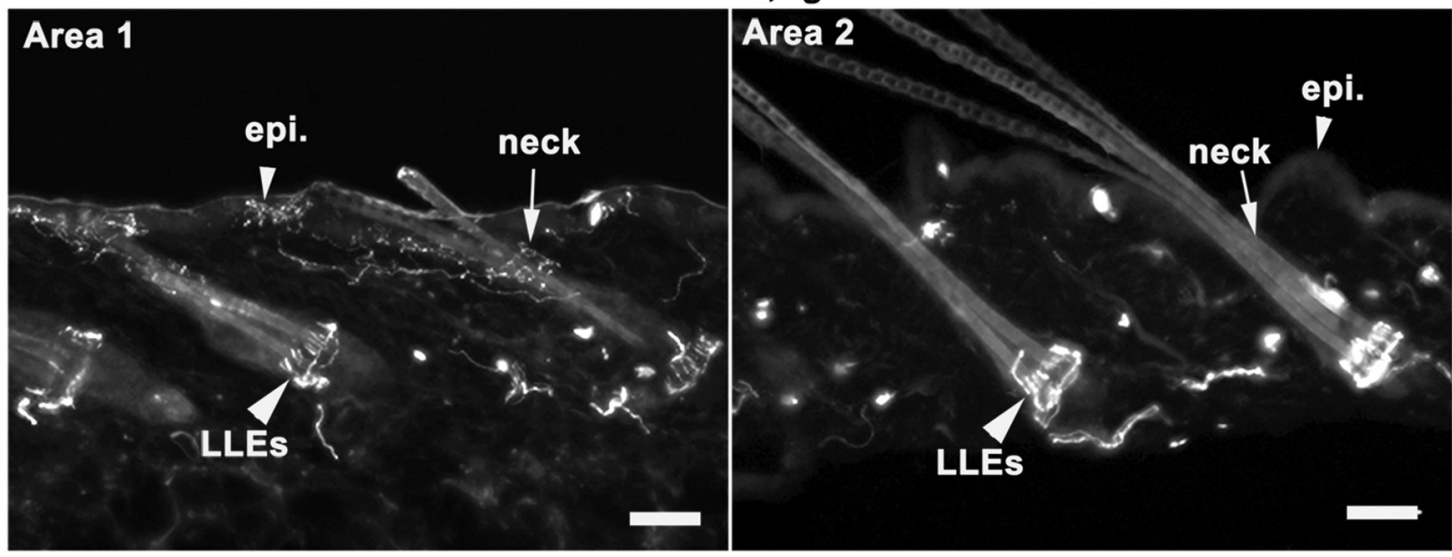

B

RunX1F/F;ROSA ${ }^{\text {tdTomato//; }} ;$ gglut3 $3^{\text {Cre/+ }}$

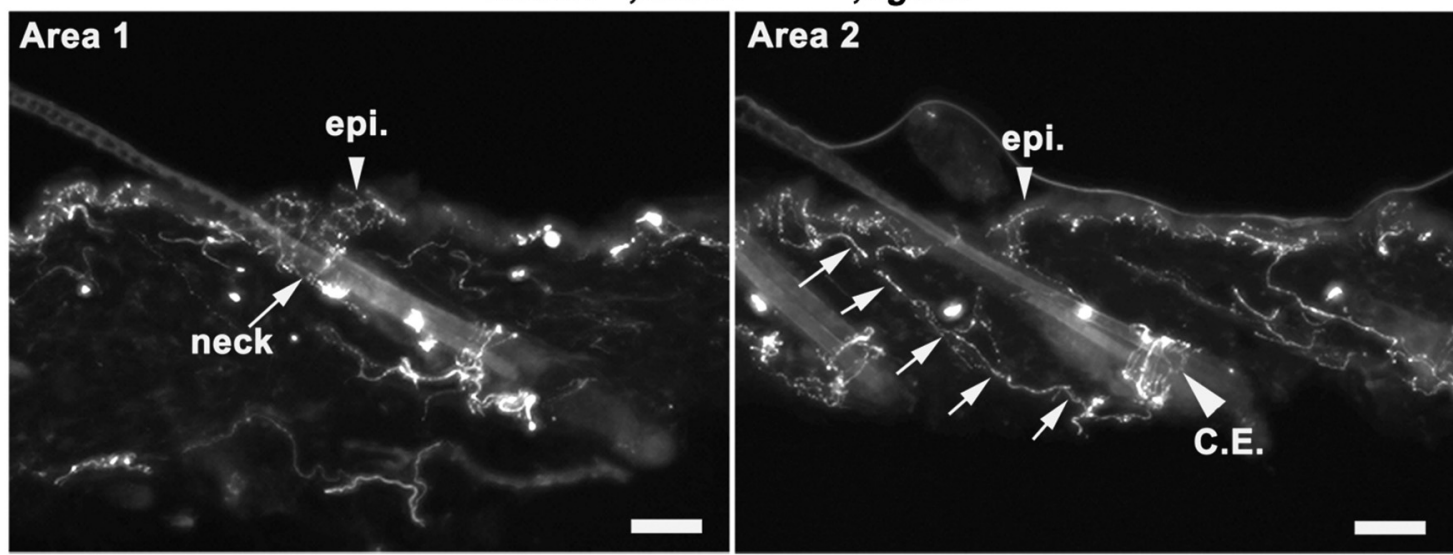

C

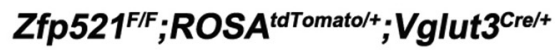
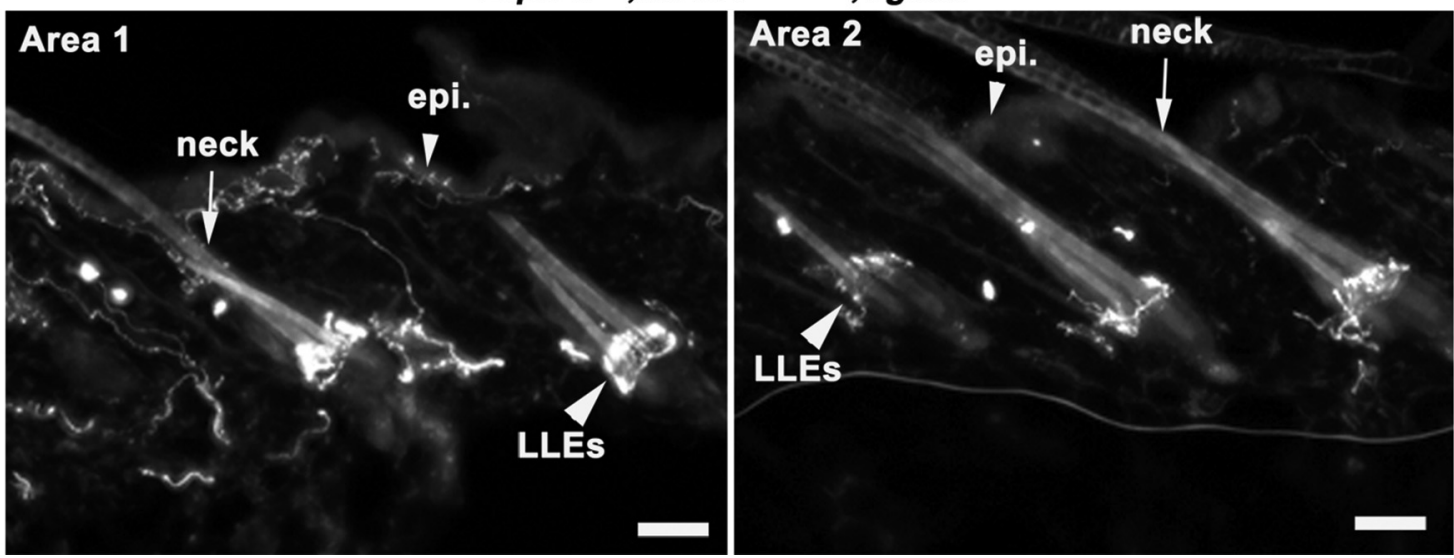

Figure 6. Skin innervation in control, Runx 1 CK0, and Zfp521 CKO mice. A, Hairy skin innervation of VGLUT3 lineage neurons in P60 control mice (ROSA26 ${ }^{\text {Tomato/+ }}$;Vglut3 $\left.{ }^{\text {Cre/+ }}\right)$. Left, Innervation of Tomato ${ }^{+}$fibers surrounding a cluster of hairs in the skin "Area 1," with the arrowhead indicating epidermal ("epi.") innervation and the arrow indicating the neck region of a hair follicle. Right, Skin "Area 2" in which VGLUT3-Tomato ${ }^{+}$fibers only form the "LLEs" (large arrowhead) without innervation to the skin epidermis (small arrowhead). B, Hairy skin innervation of VGLUT3 lineage neurons in P60 Runx 1 CK0 mice (Runx $1^{\mathrm{F} / \mathrm{F}} ;$ ROSA26 $\left.{ }^{\text {Tomato/+ }} ; \mathrm{Vglut3}{ }^{\mathrm{Cr} /+}\right)$. Arrow in left panel indicates normal innervation to the hair follicle neck region of the skin "Area 1"; arrowhead indicates normal epidermal innervation. For the right panel, large arrowhead indicates Tomato ${ }^{+}$fibers being converted from LLEs to circumferential endings ("C.E.") in skin "Area 2"; arrows indicate fibers growing toward skin surface and terminating the epidermis (small arrowhead). There was no typical innervation to the hair neck (B, right). $\boldsymbol{C}$, The innervation pattern was not changed in Zfp $521^{\mathrm{FFF}} ;$ ROSA26 $^{\text {Tomato/+ }} ; \mathrm{Vglut3}{ }^{\mathrm{Cre} /+}$ CKO mice compared with wild-type controls (A), including: (1) the retaining of "LLEs" (large arrowheads) and (2) restricted innervation to the skin epidermis (small arrowhead, left) and the neck region (arrow, left) only around a small subset of hairs ("area 1"), but not around most hairs ("area 2"). Scale bars, $50 \mu \mathrm{m}$.

out in early sensory precursors, but such loss does not occur if Runx1 is knocked out at E16-E17 (Chen et al., 2006; Abdel Samad et al., 2010). The simplest interpretation is that the $\mathrm{X}$ event is established at embryonic stages, which is required for subsequent activation of MrgprA3/B4 that normally occurs at neonatal stages (Dong et al., 2001; Chen et al., 2006; Abdel Samad et al., 2010). Once the $\mathrm{X}$ event is established, Runx1 itself is no longer required for subsequent MrgprA3/B4 expression. 
A

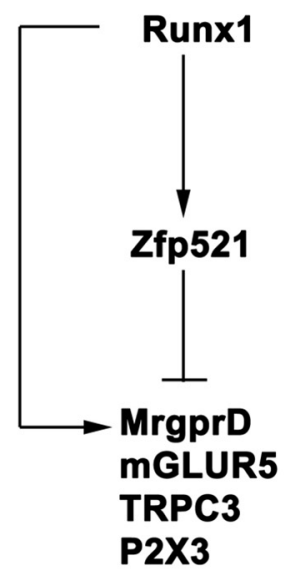

B

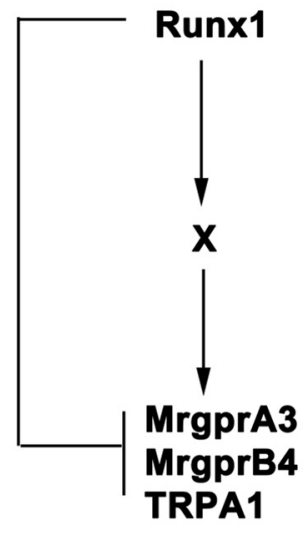

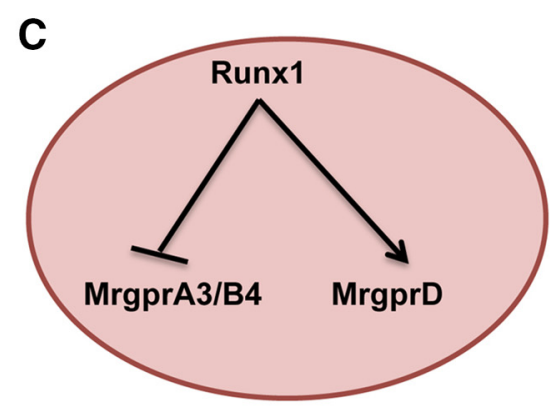

MrgprD+ nociceptors

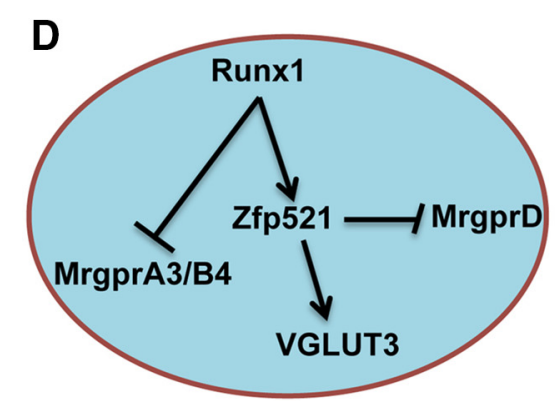

VGLUT3+ CLTMs

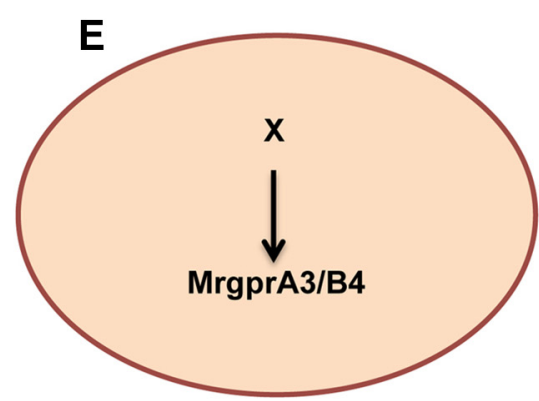

MrgprA3 ${ }^{+}$pruriceptors
MrgprB4 $^{+}$C-mechanoreceptors

Figure 7. I-FFLs control sensory subtype segregation. $\boldsymbol{A}, \boldsymbol{B}$, Runx 1 and the downstream factors form I-FFLs in controlling a distinct set of sensory channels and receptors. For details, see Discussion. The nature of the Runx1-dependent X event is unknown. $\mathbf{C}-\boldsymbol{E}$, Molecular mechanisms leading to the segregation of three types of sensory neurons. Transient Runx1 expression in MrgprA3/B4 ${ }^{+}$ neurons is not illustrated $(\boldsymbol{E})$. The arrows (" $\rightarrow$ ") or " - I" indicate the necessity of upstream factors for the activation or repression of the downstream events, not necessarily indicating a sufficiency to do so. For details, see the Discussion.

By forming these genetic I-FFLs, the same Runx1 transcription factor is now able to control the segregation of multiple cutaneous sensory neuron subtypes (Fig. 7C-E). First, the possible existence of the second I-FFL (Fig. 7B) for controlling MrgprA3/B4 expression, with Runx1 itself serving as the dominant repression leg, may explain why these two sensory receptors are normally expressed in neurons with transient Runx1 expression and are excluded from neurons with persistent Runx1 expression, such as VGLUT3 ${ }^{+}$CLTMs and MrgprD ${ }^{+}$polymodal nociceptors. Second, the I-FFL formed by Runx1 and Zfp521 (Fig. $7 A$ ), with Zfp521 serving as the dominant repression leg, allows Runx1-persistent neurons to be further segregated into two subtypes: VGLUT3 ${ }^{+}$CLTMs that express Zfp521 and MrgrpD ${ }^{+}$ polymodal nociceptors that do not express Zfp521. Such control mechanisms can explain phenotypic changes observed in various knock-out mice. In Zfp521 CKO mice, the removal of the Zfp521mediated repression leg unmasks the Runx1-mediated activation leg, allowing prospective VGLUT3 lineage neurons to acquire molecular identities of $\mathrm{MrgrpD}^{+}$neurons. In Runx1 $1^{\mathrm{F} / \mathrm{F}}$; ROSA $26^{\text {Tomato/+ }} ;$ Vglut $3^{\mathrm{Cre} /+}$ mice, neonatal knock-out of Runx 1 leads to a loss of CLTM neuron identities (due to the loss of both Runx1 and Runx1-dependent Zfp521), an inability to acquire $\mathrm{MrgprD}^{+}$neuron identities (due to the loss of Runx1-mediated activation), and a derepression of MrgprA3 and MrgprB4 (due to a loss of Runx1-mediated repression plus the establishment of the putative $\mathrm{X}$ event by Runx1 at earlier embryonic stages). As a result, prospective VGLUT3 lineage neurons acquire features that normally belong to MrgprA3 ${ }^{+}$pruriceptors or MprgprB4 ${ }^{+}$ c-mechanoreceptors in Runx1 CKO mice.

Implication on sensory coding and sensory neuron evolution In principle, the relative strength of the positive and negative legs of I-FFLs could be tuned in different cellular contexts or species. This modulation could have intriguing implication on sensory coding and sensory neuron evolutions. If the repression legs are completely dominant (i.e., Runx1-mediated repression of MrgprA3 and Zfp521-mediated repression of MrgprD), it could lead to nonoverlapped molecular expression, such as VGLUT3, MrgprD, and MrgprA3, at least at levels detected by in situ hybridization. This could form a genetic basis for the existence of modality-selective sensory neurons, such as the dedication of MrgprA3 ${ }^{+}$neurons for itch (Liu et al., 2009; Han et al., 2013). However, if the repression leg is not completely dominant, it could create variegated expression levels for the same receptors in different sensory populations, as does P2X3 (Fig. 4). Such variegated expression might form a basis for the "intensity" and "population" encoding strategies for sensory information processing (Ma, 2010, 2012; Prescott et al., 2014). For example, low dosage of a chemical stimulus might 
selectively activate neurons with highest receptor expression, whereas high dosage stimuli might additionally activate neurons with low receptor expression. According to the population coding theory, combinatorial activation of two or multiple types of sensory afferents could then generate new sensations in the brain (Ma, 2010, 2012; Prescott et al., 2014).

From an evolutionary point of view, a tuning of the relative strength of the activation versus the repression legs could create cross-species variability on the expression of sensory channels and receptors. For example, MrgprD ${ }^{+}$noiceptors do not express the itch-related MrgprA genes in mice (Dong et al., 2001), but they do coexpress MrgprA in rats (Zylka et al., 2003), which could simply be caused by a reduction in the repression leg and/or an increase in the activation leg of the I-FFLs in rats. In addition, whereas $\mathrm{TH}^{+}$CLTMs represent $6-19 \%$ of DRG neurons at different axial levels in mice (Li et al., 2011; Lou et al., 2013), none or $<1 \%$ of rat DRG neurons express TH (Price and Mudge, 1983). Therefore, a given stimulus may activate different constituents of sensory neurons in different species and, according to the population coding hypothesis, it could evoke different behaviors and perceptions (Ma, 2010, 2012; Prescott et al., 2014). Indeed, cheek injection of histamine evokes pure itch-indicating scratching responses in mice (Shimada and LaMotte, 2008), but evokes mainly pain-indicating wiping in rats (Klein et al., 2011). In addition, nape injection of chloroquine evokes robust scratching in mice (Han et al., 2013), but nearly none in rats (Klein et al., 2011). Such cross-species variability may contribute to the debate regarding to what degree a given animal species can faithfully model human pain and itch (Mogil, 2009).

\section{References}

Abdel Samad O, Liu Y, Yang FC, Kramer I, Arber S, Ma Q (2010) Characterization of two Runx1-dependent nociceptor differentiation programs necessary for inflammatory versus neuropathic pain. Mol Pain 6:45. CrossRef Medline

Alon U (2007) Network motifs: theory and experimental approaches. Nat Rev Genet 8:450-461. CrossRef Medline

Bachy I, Franck MC, Li L, Abdo H, Pattyn A, Ernfors P (2011) The transcription factor Cux2 marks development of an A-delta sublineage of TrkA sensory neurons. Dev Biol 360:77-86. CrossRef Medline

Cavanaugh DJ, Lee H, Lo L, Shields SD, Zylka MJ, Basbaum AI, Anderson DJ (2009) Distinct subsets of unmyelinated primary sensory fibers mediate behavioral responses to noxious thermal and mechanical stimuli. Proc Natl Acad Sci U S A 106:9075-9080. CrossRef Medline

Chen CL, Broom DC, Liu Y, de Nooij JC, Li Z, Cen C, Samad OA, Jessell TM, Woolf CJ, Ma Q (2006) Runxl determines nociceptive sensory neuron phenotype and is required for thermal and neuropathic pain. Neuron 49:365-377. CrossRef Medline

Delfini MC, Mantilleri A, Gaillard S, Hao J, Reynders A, Malapert P, Alonso S, François A, Barrere C, Seal R, Landry M, Eschallier A, Alloui A, Bourinet E, Delmas P, Le Feuvre Y, Moqrich A (2013) TAFA4, a chemokine-like protein, modulates injury-induced mechanical and chemical pain hypersensitivity in mice. Cell Rep 5:378-388. CrossRef Medline

Dong X, Han S, Zylka MJ, Simon MI, Anderson DJ (2001) A diverse family of GPCRs expressed in specific subsets of nociceptive sensory neurons. Cell 106:619-632. CrossRef Medline

Draxler P, Honsek SD, Forsthuber L, Hadschieff V, Sandkühler J (2014) VGluT3 ${ }^{+}$primary afferents play distinct roles in mechanical and cold hypersensitivity depending on pain etiology. J Neurosci 34:12015-12028. CrossRef Medline

Dykes IM, Lanier J, Eng SR, Turner EE (2010) Brn3a regulates neuronal subtype specification in the trigeminal ganglion by promoting Runx expression during sensory differentiation. Neural Dev 5:3. CrossRef Medline

Gorokhova S, Gaillard S, Urien L, Malapert P, Legha W, Baronian G, Desvignes JP, Alonso S, Moqrich A (2014) Uncoupling of molecular maturation from peripheral target innervation in nociceptors expressing a chimeric TrkA/TrkC receptor. PLoS Genet 10:e1004081. CrossRef Medline

Growney JD, Shigematsu H, Li Z, Lee BH, Adelsperger J, Rowan R, Curley DP, Kutok JL, Akashi K, Williams IR, Speck NA, Gilliland DG (2005) Loss of Runxl perturbs adult hematopoiesis and is associated with a myeloproliferative phenotype. Blood 106:494-504. CrossRef Medline

Han L, Ma C, Liu Q, Weng HJ, Cui Y, Tang Z, Kim Y, Nie H, Qu L, Patel KN, Li Z, McNeil B, He S, Guan Y, Xiao B, Lamotte RH, Dong X (2013) A subpopulation of nociceptors specifically linked to itch. Nat Neurosci 16:174-182. CrossRef Medline

Hesse E, Saito H, Kiviranta R, Correa D, Yamana K, Neff L, Toben D, Duda G, Atfi A, Geoffroy V, Horne WC, Baron R (2010) Zfp521 controls bone mass by HDAC3-dependent attenuation of Runx2 activity. J Cell Biol 191:1271-1283. CrossRef Medline

Julius D (2013) TRP channels and pain. Annu Rev Cell Dev Biol 29:355384. CrossRef Medline

Kamiya D, Banno S, Sasai N, Ohgushi M, Inomata H, Watanabe K, Kawada M, Yakura R, Kiyonari H, Nakao K, Jakt LM, Nishikawa S, Sasai Y (2011) Intrinsic transition of embryonic stem-cell differentiation into neural progenitors. Nature 470:503-509. CrossRef Medline

Kang S, Akerblad P, Kiviranta R, Gupta RK, Kajimura S, Griffin MJ, Min J, Baron R, Rosen ED (2012) Regulation of early adipose commitment by Zfp521. PLoS Biol 10:e1001433. CrossRef Medline

Klein A, Carstens MI, Carstens E (2011) Facial injections of pruritogens or algogens elicit distinct behavior responses in rats and excite overlapping populations of primary sensory and trigeminal subnucleus caudalis neurons. J Neurophysiol 106:1078-1088. CrossRef Medline

Lagerström MC, Rogoz K, Abrahamsen B, Persson E, Reinius B, Nordenankar K, Olund C, Smith C, Mendez JA, Chen ZF, Wood JN, Wallén-Mackenzie A, Kullander K (2010) VGLUT2-dependent sensory neurons in the TRPV1 population regulate pain and itch. Neuron 68:529-542. CrossRef Medline

Lallemend F, Ernfors P (2012) Molecular interactions underlying the specification of sensory neurons. Trends Neurosci 35:373-381. CrossRef Medline

Li L, Rutlin M, Abraira VE, Cassidy C, Kus L, Gong S, Jankowski MP, Luo W, Heintz N, Koerber HR, Woodbury CJ, Ginty DD (2011) The functional organization of cutaneous low-threshold mechanosensory neurons. Cell 147:1615-1627. CrossRef Medline

Liu P, Jenkins NA, Copeland NG (2003) A highly efficient recombineeringbased method for generating conditional knockout mutations. Genome Res 13:476-484. CrossRef Medline

Liu Q, Vrontou S, Rice FL, Zylka MJ, Dong X, Anderson DJ (2007) Molecular genetic visualization of a rare subset of unmyelinated sensory neurons that may detect gentle touch. Nat Neurosci 10:946-948. CrossRef Medline

Liu Q, Tang Z, Surdenikova L, Kim S, Patel KN, Kim A, Ru F, Guan Y, Weng HJ, Geng Y, Undem BJ, Kollarik M, Chen ZF, Anderson DJ, Dong X (2009) Sensory neuron-specific GPCR Mrgprs are itch receptors mediating chloroquine-induced pruritus. Cell 139:1353-1365. CrossRef Medline

Liu Q, Sikand P, Ma C, Tang Z, Han L, Li Z, Sun S, LaMotte RH, Dong X (2012) Mechanisms of itch evoked by $\beta$-alanine. J Neurosci 32:1453214537. CrossRef Medline

Liu Y, Ma Q (2011) Generation of somatic sensory neuron diversity and implications on sensory coding. Curr Opin Neurobiol 21:52-60. CrossRef Medline

Liu Y, Yang FC, Okuda T, Dong X, Zylka MJ, Chen CL, Anderson DJ, Kuner $\mathrm{R}, \mathrm{Ma} \mathrm{Q}$ (2008) Mechanisms of compartmentalized expression of Mrg class G-protein-coupled sensory receptors. J Neurosci 28:125-132. CrossRef Medline

Liu Y, Abdel Samad O, Duan B, Zhang L, Tong Q, Lopes C, Ji RR, Lowell BB, Ma Q (2010) VGLUT2-dependent glutamate release from peripheral nociceptors is required to sense pain and suppress itch. Neuron 68:543556. CrossRef Medline

Lopes C, Liu Z, Xu Y, Ma Q (2012) Tlx3 and Runx1 act in combination to coordinate the development of a cohort of nociceptors, thermoceptors, and pruriceptors. J Neurosci 32:9706-9715. CrossRef Medline

Lou S, Duan B, Vong L, Lowell BB, Ma Q (2013) Runxl controls terminal morphology and mechanosensitivity of VGLUT3-expressing C-mechanoreceptors. J Neurosci 33:870-882. CrossRef Medline 
Ma Q (2010) Labeled lines meet and talk: population coding of somatic sensations. J Clin Invest 120:3773-3778. CrossRef Medline

Ma Q (2012) Population coding of somatic sensations. Neurosci Bull 28:91-99. CrossRef Medline

Ma Q, Fode C, Guillemot F, Anderson DJ (1999) Neurogenin1 and neurogenin2 control two distinct waves of neurogenesis in developing dorsal root ganglia. Genes and Development 13:1717-1728. CrossRef Medline

Madisen L, Zwingman TA, Sunkin SM, Oh SW, Zariwala HA, Gu H, Ng LL, Palmiter RD, Hawrylycz MJ, Jones AR, Lein ES, Zeng H (2010) A robust and high-throughput Cre reporting and characterization system for the whole mouse brain. Nat Neurosci 13:133-140. CrossRef Medline

Mogil JS (2009) Animal models of pain: progress and challenges. Nat Rev Neurosci 10:283-294. CrossRef Medline

Moqrich A (2014) Peripheral pain-sensing neurons: from molecular diversity to functional specialization. Cell Rep 6:245-246. CrossRef Medline

Prescott SA, Ma Q, De Koninck Y (2014) Normal and abnormal coding of somatosensory stimuli causing pain. Nat Neurosci 17:183-191. CrossRef Medline

Price J, Mudge AW (1983) A subpopulation of rat dorsal root ganglion neurones is catecholaminergic. Nature 301:241-243. CrossRef Medline

Rau KK, McIlwrath SL, Wang H, Lawson JJ, Jankowski MP, Zylka MJ, Anderson DJ, Koerber HR (2009) Mrgprd enhances excitability in specific populations of cutaneous murine polymodal nociceptors. J Neurosci 29: 8612-8619. CrossRef Medline

Ren AJ, Wang K, Zhang H, Liu A, Ma X, Liang Q, Cao D, Wood JN, He DZ, Ding YQ, Yuan WJ, Xie Z, Zhang WJ (2014) ZBTB20 regulates nociception and pain sensation by modulating TRP channel expression in nociceptive sensory neurons. Nat Commun 5:4984. CrossRef Medline

Rodríguez CI, Buchholz F, Galloway J, Sequerra R, Kasper J, Ayala R, Stewart AF, Dymecki SM (2000) High-efficiency deleter mice show that FLPe is an alternative to Cre-loxP. Nat Genet 25:139-140. CrossRef Medline

Seal RP, Wang X, Guan Y, Raja SN, Woodbury CJ, Basbaum AI, Edwards RH (2009) Injury-induced mechanical hypersensitivity requires C-low threshold mechanoreceptors. Nature 462:651-655. CrossRef Medline
Shimada SG, LaMotte RH (2008) Behavioral differentiation between itch and pain in mouse. Pain 139:681-687. CrossRef Medline

Stein R, Orit S, Anderson DJ (1988) The induction of a neural-specific gene, SCG10, by nerve growth factor in PC12 cells is transcriptional, protein synthesis dependent, and glucocorticoid inhibitable. Dev Biol 127:316325. CrossRef Medline

Sun Y, Dykes IM, Liang X, Eng SR, Evans SM, Turner EE (2008) A central role for Islet 1 in sensory neuron development linking sensory and spinal gene regulatory programs. Nat Neurosci 11:1283-1293. CrossRef Medline

Usoskin D, Furlan A, Islam S, Abdo H, Lönnerberg P, Lou D, Hjerling-Leffler J, Haeggström J, Kharchenko O, Kharchenko PV, Linnarsson S, Ernfors P (2014) Unbiased classification of sensory neuron types by large-scale single-cell RNA sequencing. Nat Neurosci 8:145-153. CrossRef Medline

Vrontou S, Wong AM, Rau KK, Koerber HR, Anderson DJ (2013) Genetic identification of $\mathrm{C}$ fibres that detect massage-like stroking of hairy skin in vivo. Nature 493:669-673. CrossRef Medline

Yang FC, Tan T, Huang T, Christianson J, Samad OA, Liu Y, Roberson D, Davis BM, Ma Q (2013) Genetic control of the segregation of painrelated sensory neurons innervating the cutaneous versus deep tissues. Cell Rep 5:1353-1364. CrossRef Medline

Yoshikawa M, Senzaki K, Yokomizo T, Takahashi S, Ozaki S, Shiga T (2007) Runx1 selectively regulates cell fate specification and axonal projections of dorsal root ganglion neurons. Dev Biol 303:663-674. CrossRef Medline

Zou M, Li S, Klein WH, Xiang M (2012) Brn3a/Pou4f1 regulates dorsal root ganglion sensory neuron specification and axonal projection into the spinal cord. Dev Biol 364:114-127. CrossRef Medline

Zylka MJ, Dong X, Southwell AL, Anderson DJ (2003) Atypical expansion in mice of the sensory neuron-specific Mrg G protein-coupled receptor family. Proc Natl Acad Sci U S A 100:10043-10048. CrossRef Medline

Zylka MJ, Rice FL, Anderson DJ (2005) Topographically distinct epidermal nociceptive circuits revealed by axonal tracers targeted to Mrgprd. Neuron 45:17-25. CrossRef Medline 